\title{
Adenosine signaling promotes hematopoietic stem and progenitor cell emergence
}

\section{Citation}

Jing, L., O. J. Tamplin, M. J. Chen, Q. Deng, S. Patterson, P. G. Kim, E. M. Durand, et al. 2015. "Adenosine signaling promotes hematopoietic stem and progenitor cell emergence." The Journal of Experimental Medicine 212 (5): 649-663. doi:10.1084/jem.20141528. http:// dx.doi.org/10.1084/jem.20141528.

\section{Published Version}

doi:10.1084/jem.20141528

\section{Permanent link}

http://nrs.harvard.edu/urn-3:HUL.InstRepos:23845295

\section{Terms of Use}

This article was downloaded from Harvard University's DASH repository, and is made available under the terms and conditions applicable to Other Posted Material, as set forth at http:// nrs.harvard.edu/urn-3:HUL.InstRepos:dash.current.terms-of-use\#LAA

\section{Share Your Story}

The Harvard community has made this article openly available.

Please share how this access benefits you. Submit a story.

\section{Accessibility}




\title{
Adenosine signaling promotes hematopoietic stem and progenitor cell emergence
}

\author{
Lili Jing, ${ }^{1,2}$ Owen J. Tamplin, ${ }^{1,2}$ Michael J. Chen, ${ }^{1,2}$ Qing Deng, ${ }^{5,6}$ \\ Shenia Patterson, ${ }^{7}$ Peter G. Kim, ${ }^{1,2,3}$ Ellen M. Durand, ${ }^{1,2}$ Ashley McNeil, $, 1,2$ \\ Julie M. Green, ${ }^{5,6}$ Shinobu Matsuura, ${ }^{7}$ Julien Ablain, ${ }^{1,2}$ Margot K. Brandt, ${ }^{1,2}$ \\ Thorsten M. Schlaeger, ${ }^{1,2}$ Anna Huttenlocher, ${ }^{5,6}$ George Q. Daley, ${ }^{1,2,3}$ \\ Katya Ravid, ${ }^{7}$ and Leonard I. Zon ${ }^{1,2,3,4}$
}

\author{
'Stem Cell Program, Division of Hematology/Oncology, Boston Children's Hospital and Dana-Farber Cancer Institute, \\ Boston, MA 02115 \\ ${ }^{2}$ Harvard Stem Cell Institute, ${ }^{3}$ Howard Hughes Medical Institute, and ${ }^{4}$ Department of Stem Cell and Regenerative Biology, \\ Harvard University, Cambridge, MA 02138 \\ ${ }^{5}$ Department of Medical Microbiology and Immunology and ${ }^{6}$ Department of Pediatrics, University of Wisconsin-Madison, \\ Madison, WI 53706 \\ ${ }^{7}$ Department of Medicine, Boston University School of Medicine and the Evans Center for Interdisciplinary Biomedical Research, \\ Boston, MA 02118
}

Hematopoietic stem cells (HSCs) emerge from aortic endothelium via the endothelial-tohematopoietic transition (EHT). The molecular mechanisms that initiate and regulate EHT remain poorly understood. Here, we show that adenosine signaling regulates hematopoietic stem and progenitor cell (HSPC) development in zebrafish embryos. The adenosine receptor $A_{2 b}$ is expressed in the vascular endothelium before HSPC emergence. Elevated adenosine levels increased runx $1^{+} / \mathrm{cmy} b^{+}$HSPCs in the dorsal aorta, whereas blocking the adenosine pathway decreased HSPCs. Knockdown of $A_{2 b}$ adenosine receptor disrupted scl $^{+}$hemogenic vascular endothelium and the subsequent EHT process. $A_{2 b}$ adenosine receptor activation induced CXCL8 via CAMP-protein kinase A (PKA) and mediated hematopoiesis. We further show that adenosine increased multipotent progenitors in a mouse embryonic stem cell colony-forming assay and in embryonic day 10.5 aorta-gonad-mesonephros explants. Our results demonstrate that adenosine signaling plays an evolutionary conserved role in the first steps of HSPC formation in vertebrates.

\section{CORRESPONDENCE}

Leonard I. Zon:

zon@enders.tch.harvard.edu

Abbreviations used: AGM, aorta-gonad-mesonephros; CHT, caudal hematopoietic tissue; EB, embryoid body; EHT, endothelial-to-hematopoietic transition; ESC, embryonic stem cell; HAEC, human aortic endothelial cell; HE, hemogenic endothelium; hpf, hour postfertilization; HSC, hematopoietic stem cell; HSPC, hematopoietic stem and progenitor cell; $\mathrm{mESC}$, mouse ESC; MO, morpholino; NECA, $5^{\prime}-N$-ethylcarboxamidoadenosine; PKA, protein kinase $\mathrm{A}$; qPCR, quantitative PCR; TALEN, transcription activator-like effector nuclease.
Hematopoietic stem cells (HSCs) are a reservoir of rare, multipotent stem cells that provide a continuous supply of various hematopoietic lineages circulating in the blood (Orkin and Zon, 2008). It is of great therapeutic interest to generate transplantable HSCs from human embryonic stem cells (ESCs) or induced pluripotent stem cells. Despite many years of studies, such in vitro bona-fide HSC generation has proven difficult, which is partly the result of our incomplete understanding of the pathways that regulate HSC formation during development.

In the embryo, HSCs are first specified in the aorta-gonad-mesonephros (AGM) region (Medvinsky and Dzierzak, 1996). HSCs derive directly from a unique population of aorta endothelial cells termed hemogenic endothelium (HE; Yoshimoto and Yoder, 2009). By in vivo time-lapse confocal imaging, recent studies have captured the emergence of HSCs from the ventral aorta endothelium through a process known as the endothelial-to-hematopoietic transition (EHT; Bertrand et al., 2010; Boisset et al., 2010; Kissa and Herbomel, 2010). During this process, hemogenic endothelial cells bend, round up to transform to HSCs, and release from the aorta ventral wall to the vascular lumen. Previous studies have identified pivotal transcription factors that regulate this process. $r u n x 1$, a central player expressed in HE and nascent HSCs, is essential for the transformation of hemogenic endothelial cells to HSCs (Okuda et al., 1996; Wang et al., 1996; Chen et al., 2009). Additionally, scl,

Q 2015 Jing et al. This article is distributed under the terms of an AttributionNoncommercial-Share Alike-No Mirror Sites license for the first six months after Noncommercial-Share Alike-No Mirror Sites license for the first six months after
the publication date (see http://www.rupress.org/terms). After six months it is available under a Creative Commons License (Attribution-Noncommercial-Share Alike 3.0 Unported license, as described at http://creativecommons.org/licenses/ by-nc-sa/3.0/) 
gata2, and sox 17 also regulate different steps in this developmental transition (Tsai et al., 1994; Porcher et al., 1996; Kim et al., 2007). Hematopoietic transcription factors are activated by extrinsic signals. Growth factors and morphogens such as bone morphogenic protein 4 (BMP4), Notch, Hedgehog, FGF, Wnt, and vascular endothelial growth factor (VEGF), from the surrounding endothelial or mesenchymal cells, control the hematopoietic program (for review see Kaimakis et al. [2013]).

One group of factors that may participate in the induction of HSCs is purinergic signals. Purines (such as adenosine, ADP, and ATP) exhibit specific extracellular signaling activity in the regulation of many diverse functions including autoregulation of blood flow, cell proliferation and differentiation, and stem cell regeneration (Glaser et al., 2012; Rossi et al., 2012). Many of these functions act through cell surface receptors (Rossi et al., 2012). Extracellular adenosine is hydrolyzed from ATP by ectonucleotidases, and its level is elevated as oxygen supply decreases or energy demand increases (Haskó et al., 2008). Adenosine acts at four distinct G-protein-coupled receptors $\left(A_{1}\right.$ and $A_{3}$ adenylyl cyclase-inhibitory and $A_{2 a}$ and $A_{2 b}$ adenylyl cyclase-stimulatory receptors; for review see Koupenova et al. [2012]) and has been shown to regulate early development, such as modulating embryo cardiac function via the $A_{1}$ receptor (Funakoshi et al., 2006). Accumulating evidence also suggests that adenosine signaling has a role in hematopoietic cells. Adenosine signaling induces the proliferation and differentiation of hematopoietic progenitor cells in the lymph gland of Drosophila melanogaster embryos (Mondal et al., 2011). In the adult mice, administration of drugs that elevate extracellular adenosine levels increases hematopoietic spleen colony formation in sublethally gamma-irradiated animals (Hofer et al., 1997) and enhances cell cycling of hematopoietic progenitor cells (Pospísil et al., 2001). These observations together indicate a potential role of adenosine in regulating HSCs.

In zebrafish, runx1- and cmyb-expressing hematopoietic stem and progenitor cells (HSPCs) first appear along the ventral wall of the dorsal aorta (functionally equivalent to AGM in mouse). These HSPCs will later colonize the caudal hematopoietic tissue (CHT; equivalent to mouse fetal liver) and eventually reside in definitive hematopoietic organs, the thymus and kidney marrow (Chen and Zon, 2009). Through an in vivo screening approach, we identified the adenosine pathway as an enhancer of HSPC development. We show that adenosine signaling mediates $r u n x 1^{+} / c m y b^{+}$HSPCs by regulating the $\mathrm{HE}$ and its transition to hematopoietic cells. Adenosine exerts this effect primarily through the $A_{2 b}$ adenosine receptor in a cAMP-protein kinase A (PKA)-dependent pathway. In addition, adenosine regulates the production of CXCL8 and mediates hematopoiesis partly through CXCL8. We also show that adenosine promotes hematopoietic colony formation and increases multipotent progenitors in mouse ESC (mESC) culture and embryonic day (E) 10.5 AGM explants. Our findings identify an important role of adenosine signaling in HSPC emergence.

\section{RESULTS}

Adenosine regulates the formation of HSCs

To identify novel pathways that expand HSC development in the CHT of zebrafish, we have conducted an in vivo chemical screen (Tamplin et al., 2015). In this screen, wild-type embryos were incubated with individual chemicals from $48 \mathrm{~h}$ postfertilization (hpf) to $72 \mathrm{hpf}$ and examined at $72 \mathrm{hpf}$ for alterations of $r u n x 1^{+} / c m y b^{+}$HSPCs in the CHT. Approximately 2,400 compounds were screened, and three identified chemicals that increased $r u n \times 1^{+} / c m y b^{+}$cells in the CHT were related to the adenosine signaling pathway: [2-chloro-N6-(3iodobenzyl)adenosine- 5 '-N-methylcarboxamide] (Chloro-IBMECA),(2S)-N6-[2-endo-Norbornyl]adenosine ((S)-ENBA; adenosine receptor agonists), and erythro-9-(2-Hydroxy-3nonyl)adenine (EHNA) hydrochloride (an adenosine deaminase inhibitor). Follow-up live-imaging experiments revealed that the increased HSPCs in the CHT after adenosine treatment came from more production in the AGM (not depicted). This observation prompted us to examine the role of adenosine in AGM HSPC formation.

We treated wild-type embryos with different adenosine analogues (including the screen hits) and examined their effect on HSC development in the ventral wall of dorsal aorta. Among the chemicals tested, the most potent enhancer is $5^{\prime}$-N-ethylcarboxamidoadenosine (NECA), a robust adenosine receptor agonist, with preference toward $\mathrm{A}_{2}$-type adenosine receptors. As shown in Fig. 1, NECA significantly increased runx 1/cmyb expression (Fig. 1, A-B'). Conversely, CGS15943, a potent adenosine receptor nonselective antagonist, decreased run $x 1^{+} / c m y b^{+}$HSPCs (Fig. 1, C and $\mathrm{C}^{\prime}$ ). The effect of these chemicals on hematopoiesis was dose dependent and most potent when continuously treating the embryos from early somitogenesis (5-somite stage) to $36 \mathrm{hpf}$. It is known that adenosine signaling plays a role in cardiovascular function (Haskó et al., 2008), so we examined whether exposure to adenosine analogues altered vascular formation or blood circulation, but they appeared normal at the stages we studied (Fig. 1, $E^{\prime}-G^{\prime}$; and not depicted).

To examine whether the effect of adenosine is to increase the expression of HSPC genes or the number of HSPCs, we added an adenosine receptor agonist and antagonist to $\operatorname{Tg}($ cm $y b$ : eGFP; flk1:mcherry) embryos, in which HSCs and progenitors are marked by coexpression of both fluorescent proteins (Yue et al., 2012). We found that the number of HSPCs in these embryos was significantly increased after NECA treatment $(4.4 \pm 0.4$ /somite vs. $3.6 \pm 0.2 /$ somite [con] $)$ and significantly decreased after CGS15943 exposure (3.0 \pm 0.2 /somite; Fig. 1 , $\mathrm{D}-\mathrm{H})$. These data indicate that adenosine increases HSPC numbers rather than acting on gene expression alone. Therefore, adenosine regulates definitive hematopoiesis during development, and likely via an effect on an adenosine receptor.

\section{Adenosine-regulated HSPC formation is primarily through $A_{2 b}$ adenosine receptor}

Adenosine signaling exerts its effect by activating G proteincoupled receptors on target cells. Four adenosine receptors, 

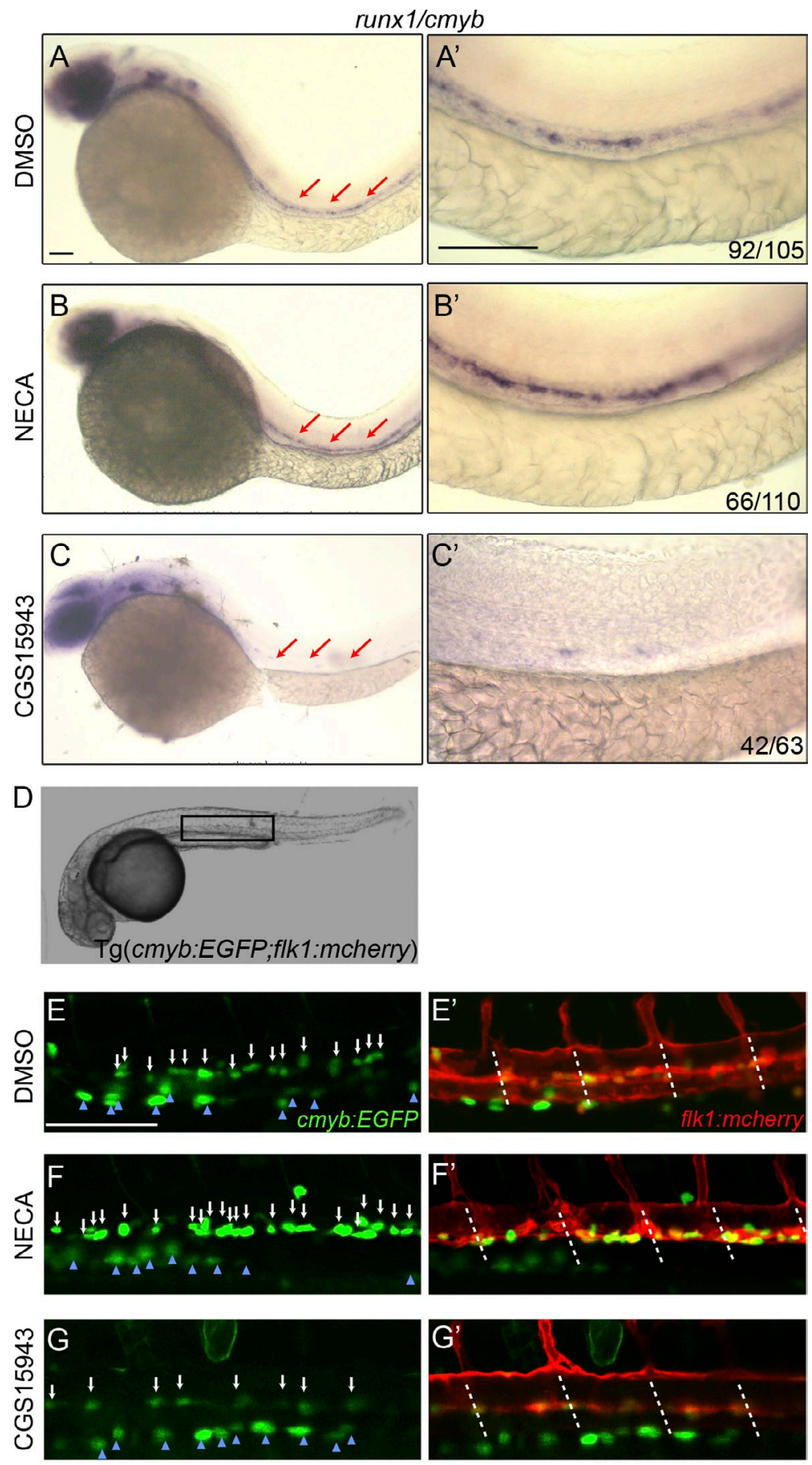

Figure 1. An adenosine analogue regulates definitive hematopoiesis. (A-C') In situ hybridization of runx $1 / \mathrm{cmyb}$ at $36 \mathrm{hpf}$. Representative images of wild-type embryos treated with DMSO ( $A$ and $\left.A^{\prime}\right)$, adenosine receptor agonist NECA $\left(20 \mu \mathrm{M} ; \mathrm{B}\right.$ and $\left.\mathrm{B}^{\prime}\right)$, and antagonist (10 $\mu \mathrm{M}$ CGS15943; $\mathrm{C}$ and $\left.\mathrm{C}^{\prime}\right)$. Prime panels depict the AGM region of the embryos in $A-C$ (red arrows). The numbers at the right corner (here and following) indicate embryos with altered HSPC staining over the total number of embryos examined. (D) Bright view of Tg(cmyb:GFP; flk1:mcherry) embryos. The square indicates the live-imaging position. (E-G') Confocal images of doubletransgenic embryos at $36 \mathrm{hpf}$. The embryos were treated with DMSO ( $E$ and $E^{\prime}$ ), NECA ( $F$ and $F^{\prime}$ ), or CGS15943 ( $G$ and $G^{\prime}$ ). The white arrows point to the double-positive HSPCs in the aorta region. The blue arrowheads point to the multiciliate cells of the pronephros. Dashed lines indicate the somite boundaries. (H) Quantification of the number of HSPCs per somite in Tg(cmyb:GFP; flk1:mcherry) embryos at $36 \mathrm{hpf}$. The results are presented as mean \pm SE (Student's $t$ test: ${ }^{*}, \mathrm{P}<0.05 ; n=5-8$ per group). Bars, $100 \mu \mathrm{m}$.

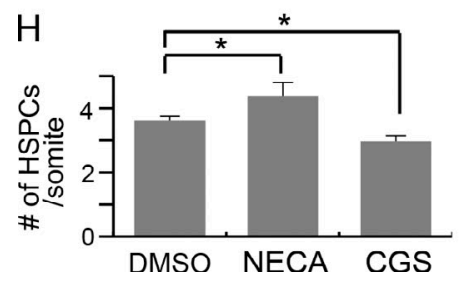

$A_{1}, A_{2 a}, A_{2 b}$, and $A_{3}$, have been identified. Each receptor has a distinct cellular and tissue distribution and modulates different biological functions (Haskó et al., 2008). We focused on
$\mathrm{A}_{2 \mathrm{a}}$ and $\mathrm{A}_{2 \mathrm{~b}}$ adenosine receptors (denoted here as $\mathrm{A}_{2 \mathrm{a}}$ and $\mathrm{A}_{2 \mathrm{~b}}$ ) because of their enrichment in endothelial and hematopoietic cells (Adair, 2005; Rossi et al., 2012) and because of the 


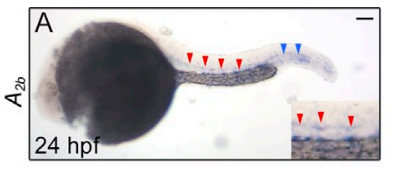

WT

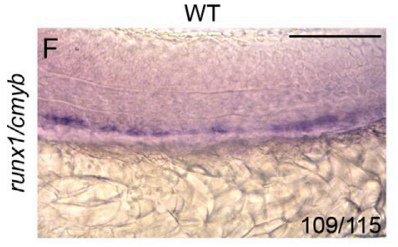

DMSO

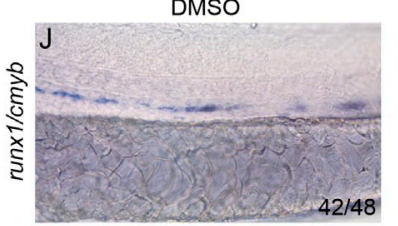

WT
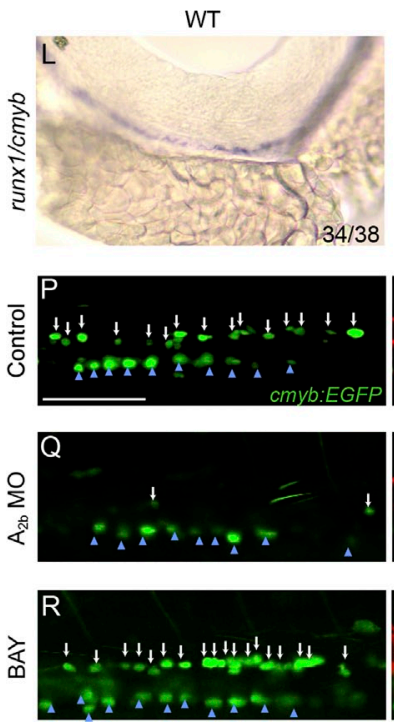

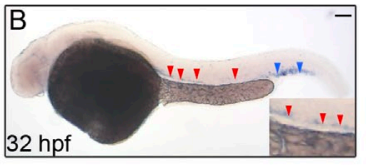

$\mathrm{A}_{2 b} \mathrm{MO}$

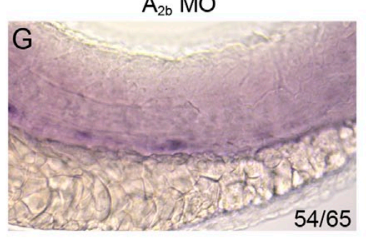

BAY

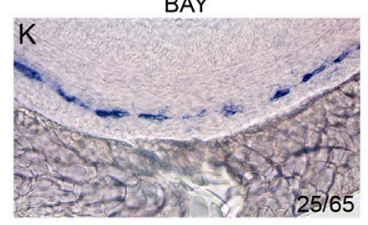

$\mathrm{A}_{2 \mathrm{~b}} \mathrm{SPMO}$
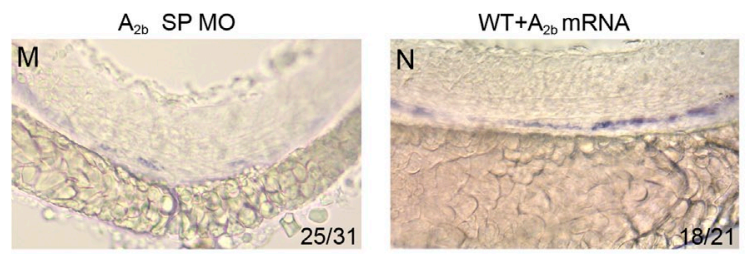

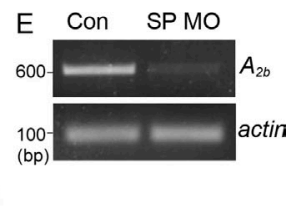

$A_{2 b} M O+h A_{2 b}$ mRNA
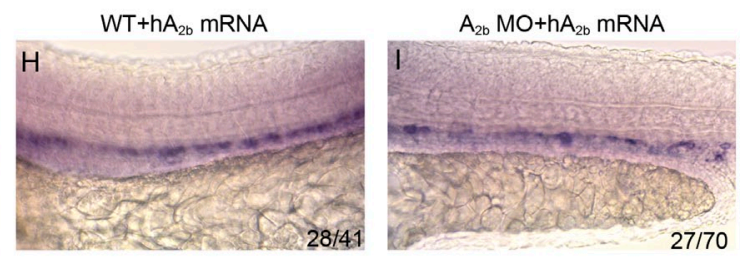

$27 / 70$
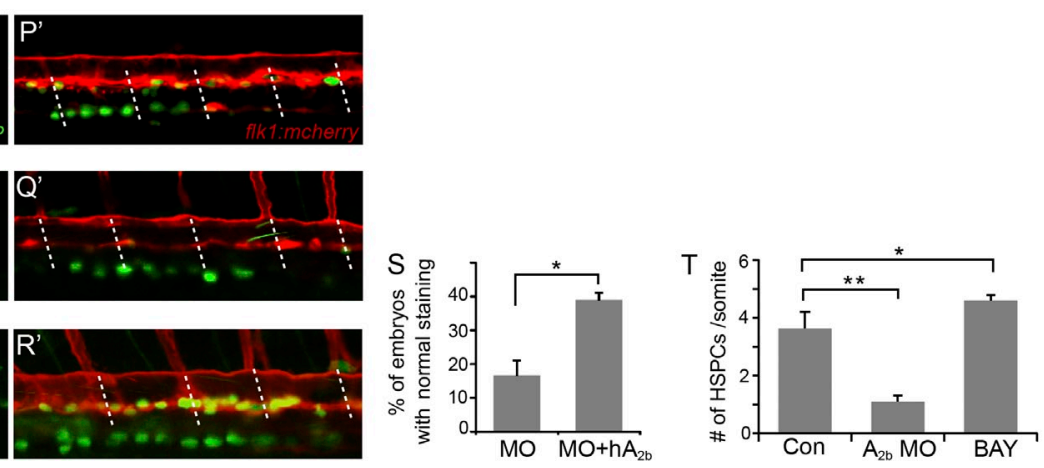

Figure 2. Adenosine functions through $A_{2 b}$ to regulate HSPC formation. ( $A$ and $B$ ) In situ hybridization of $A_{2 b}$ at $24(A)$ and 32 hpf (B). $A_{2 b}$ is expressed in the vasculature of the AGM (red arrowheads) and the CHT (blue arrowheads). Insets are enlarged images of the AGM. (C) qPCR analysis of $A_{2 b}$ expression in flk1:GFP' FACS-sorted cells compared with flk1:GFP- cells at 23, 28, and 32 hpf. Results are shown as fold change of GFP+ to GFP- $^{-}$cells and normalized to expression of $\beta$-actin mRNA (Student's $t$ test: ${ }^{*}, P<0.05 ; n=3$ samples). (D) qPCR analysis of $A_{2 b}$ expression in flk 1:GFP+ cells from control or sih morphant embryos at the indicated stages: 16 and $23 \mathrm{hpf}$ (before circulation) and $28 \mathrm{hpf}$ (after circulation starts). Results are shown as fold change relative to $A_{2 b}$ level at $16 \mathrm{hpf}$ and normalized to expression of $\beta$-actin mRNA (Student's $t$ test: ${ }^{*}, P<0.05 ; n=3$ samples). (E) RT-PCR on uninjected or $A_{2 b}$ splicing MO (A $A_{2 b}$ SP MO, here and following)-injected embryos with $A_{2 b}$ or actin-specific primers. Note the absence of correctly spliced $A_{2 b}$ transcript after $M 0$ injection. (F-I) Expression of runx $1 /$ cmyb at $36 \mathrm{hpf}$ in the AGM of control embryos (F), embryos injected with $\mathrm{A}_{2 b} \mathrm{MO}(\mathrm{G})$, and $\mathrm{hA}_{2 b}$ mRNA-injected (H) and $\mathrm{A}_{2 b} \mathrm{MO}$ - and hA $\mathrm{A}_{2 b}$ mRNA-co-injected embryos (I). The numbers in each panel are combined from multiple experiments. ( $\mathrm{J}$ and $\mathrm{K}$ ) Expression of runx $1 / \mathrm{cmyb}$ at $36 \mathrm{hpf}$ in control embryos (J) and embryos treated with $10 \mu \mathrm{M}$ BAY 60-6583 (K). (L-0) Expression of runx $1 /$ cmyb at $36 \mathrm{hpf}$ in the AGM of control embryos (L) and $\mathrm{A}_{2 b} \mathrm{SP} \mathrm{MO}-$ injected (M), $\mathrm{zA}_{2 b}$ mRNA-injected (N), and $\mathrm{A}_{2 b} \mathrm{SP} M \mathrm{MO}$ - and $\mathrm{zA}_{2 b}$ mRNA-co-injected embryos (0). (P-R') Confocal images of Tg(cmyb:GFP; flk1:mcherry) embryos at 36 hpf. Control embryos ( $P$ and $\left.P^{\prime}\right)$, embryos injected with $A_{2 b} M O\left(Q\right.$ and $\left.Q^{\prime}\right)$, and embryos treated with $10 \mu M$ BAY 60-6583 (R and R') are shown. White arrows mark the double-positive HSPCs. Blue arrowheads point to the pronephros. White dashed lines mark somite boundaries. (S) Quantification of the experiments in $\mathrm{G}$ and $\mathrm{I}$. The results are presented as the mean percentage of embryos with restored runx $1 / \mathrm{cmyb}$ staining as in I \pm SE (Student's $t$ test: *, $P<0.05 ; n=3$ independent experiments, 20-25 embryos per experiment). (T) Quantification of number of HSPCs per somite in Tg(cmyb:GFP; flk1:mcherry) embryos. The results are presented as mean \pm SE (Student's $t$ test: ${ }^{*}, \mathrm{P}<0.05 ;{ }^{* *}, \mathrm{P}<0.01 ; n=5-8$ embryos per group). Bars, $100 \mu \mathrm{m}$.

above-described effect of NECA (an $\mathrm{A}_{2}$-type adenosine receptor agonist). We designed morpholinos (MOs) to knock down the two receptors and identified $\mathrm{A}_{2 \mathrm{~b}}$ as an important player in HSC development.
During embryo development, $A_{2 b}$ is predominantly expressed in the vasculature within the AGM and CHT (Fig. 2, $\mathrm{A}$ and $\mathrm{B}$ ), which is consistent with the previous findings (Boehmler et al., 2009). Real-time quantitative PCR (qPCR) 
analysis confirmed that $\mathrm{A}_{2 \mathrm{~b}}$ is enriched in FACS-sorted flk1: $\mathrm{GFP}^{+}$endothelial cells from 20-somite stage to $40 \mathrm{hpf}$ (Fig. $2 \mathrm{C}$ and not depicted). We found that $A_{2 b}$ expression in endothelial cells is elevated shortly before the circulation starts and HSPCs emerge and that $\mathrm{A}_{2 \mathrm{~b}}$ expression is strongly reduced in embryos injected with silent heart (sih) MOs that lack a heartbeat and blood circulation (Fig. 2 D). These results suggest that circulation is required to maintain $\mathrm{A}_{2 \mathrm{~b}}$ expression, but not for induction of expression.

We used a translation-blocking $\mathrm{MO}$ and a splice $\mathrm{MO}$ to block the $\mathrm{A}_{2 \mathrm{~b}}$ receptor. We confirmed that the splicing $\mathrm{MO}$ inhibits $A_{2 b}$ splicing (Fig. 2 E). Knockdown of $A_{2 b}$ using either $\mathrm{MO}$ did not affect the general development of the embryos (not depicted) but caused a strong reduction of runx $1 /$ cm $y b$ in the AGM (Fig. 2, F, G, L, and M). Injection of zebrafish $A_{2 b}$ mRNA rescued the expression of runx $1 / c m y b$ in $A_{2 b}$ splicing $\mathrm{MO}-$-injected embryos (Fig. 2, $\mathrm{N}$ and $\mathrm{O}$ ), and injection of human $\mathrm{A}_{2 \mathrm{~b}}$ mRNA partially rescued runx 1/cmyb in the embryos injected with $\mathrm{A}_{2 \mathrm{~b}}$ translation-blocking $\mathrm{MO}$ (Fig. 2, H, I, and S), which supports the specificity of $\mathrm{MO}$ targeting. In addition, we injected $\mathrm{A}_{2 \mathrm{~b}} \mathrm{MO}$ into $\mathrm{p} 53^{-1-}$ mutant embryos to attenuate the off-target effect (Robu et al., 2007), and we saw similar phenotypes in $p 53$ mutant embryos (not depicted), which also supports that the observed HSPC defects are caused by specific loss of $A_{2 b}$ function. The robust phenotype after blocking $A_{2 b}$ function prompted us to examine the effect of an $A_{2 b}$ receptor selective agonist (BAY 60-6583; Koupenova et al., 2012) in zebrafish embryos. As expected, BAY 60-6583 significantly increased the expression of $\operatorname{runx} 1 / \mathrm{cm} y b$ (Fig. 2, $\mathrm{J}$ and $\mathrm{K}$ ).

Consistent with the runx 1/cmyb staining, knockdown of $\mathrm{A}_{2 \mathrm{~b}}$ in $\operatorname{Tg}(c m y b$ : GFP; flk1:mcherr $)$ reduced the double fluorescentlabeled HSPCs $(1.1 \pm 0.2 /$ somite vs. $3.6 \pm 0.6 /$ somite [con] $)$. BAY 60-6583 treatment increased the number of HSPCs in the $\operatorname{Tg}($ (cmyb:GFP; flk1:mcherry) embryos (4.6 \pm 0.3/somite; Fig. 2, $\mathrm{P}-\mathrm{R}^{\prime}$ and $\left.\mathrm{T}\right)$. Alterations of adenosine signaling with either treatment did not have an effect on the GFP-labeled cells in the pronephros (Fig. 2, P-R).

Compared with $c m y b$, run $x 1$ is more specifically expressed in nascent HSCs. We examined embryos using runx 1 probe alone and found that knockdown of $\mathrm{A}_{2 \mathrm{~b}}$ strongly reduced $\operatorname{run} \times 1^{+}$cells (Fig. 3, A and B). We also studied hematopoiesis and subsequent lineage differentiation at later time points after $A_{2 b}$ inhibition. $A_{2 b}$ morphants have reduced runx $1^{+} /$ $c m y b^{+}$HSPCs in the CHT at 60 hpf (Fig. 3, C and D), reduced $c m y b^{+}$multipotent progenitor cells in the CHT at $4.5 \mathrm{~d}$ postfertilization (dpf; Fig. 3, E and F), and reduced rag $1^{+}$thymic T cells (Fig. 3, G and H). Together, our results indicate that $\mathrm{A}_{2 \mathrm{~b}}$ regulates HSPC development.

To determine the specificity of loss of $\mathrm{A}_{2 \mathrm{~b}}$-induced HSPC defects, we examined the development of other tissues. $A_{2 b}$ morphant embryos demonstrated normal heart beating and circulation (not depicted). Those embryos developed normal vasculature differentiation, as shown by the normal expression of flk1:mcherry (Fig. 2, $\mathrm{P}^{\prime}-\mathrm{Q}^{\prime}$ ), the vessel marker $f l k 1$, the artery marker EphB2, and the normal intersegment vessels (flk1 and flk1:mcherry), pronephros (cd1h17), and somite (myoD; Fig. 3, I-P). In addition, $\mathrm{A}_{2 \mathrm{~b}} \mathrm{MO}-$-injected embryos showed normal primitive erythroid cells (gata1) and angioblasts ( $\mathrm{scl}$; Fig. 3, Q-T). The transient expression of cm $y b$ and runx 1 in early somite-stage embryos was not affected (Fig. 3, U-X). These results support that the defects in HSPC specification in the absence of $A_{2 b}$ are highly specific, not caused by deficits from the nearby tissues.

\section{Adenosine promotes hematopoietic development in mESC culture and in mouse AGM explant}

To test whether adenosine signaling would have an effect on mammalian hematopoiesis, we assessed the effect of adenosine on the development of mouse HSPC populations. We first used an mESC hematopoietic differentiation system, an accessible in vitro model which recapitulates mouse embryonic hematopoiesis (Kim et al., 2013). In this model, mESCs are aggregated into embryoid bodies (EBs) and differentiated into primitive streak-like mesoderm on day 2 , hemangioblasts on day 3.25, and hematopoietic precursors after day 5. $\mathrm{A}_{2 \mathrm{~b}}$ receptor is present between days 0 and 6 of EB differentiation (not depicted). Analysis of gene expression data in sorted populations from day 6 EBs (Kim et al., 2013) showed that $A_{2 b}$ is high in the VE-cadherin ${ }^{+} \mathrm{CD} 41^{-}$endothelial cells and low in the $\mathrm{CD}_{4} 1^{+}$populations (Fig. $4 \mathrm{~A}$ ), indicating that $\mathrm{A}_{2 \mathrm{~b}}$ likely regulates $\mathrm{VE}$-cadherin ${ }^{+}$cell intermediates, a fraction from which HSCs emerge. Methylcellulose-based colony-forming assay was performed to measure both hematopoietic progenitor types and numbers. Addition of $\mathrm{A}_{2 \mathrm{~b}}$ selective agonist BAY 60-6583 to EBs between days 4 and 6 significantly increased the number of hematopoietic colonies, including definitive erythroid (CFU-E), granulocyte/monocyte (CFU-GM), and multipotent granulocyte/erythrocyte/monocyte/macrophage (CFU-E/GM/GEMM) colonies, at a concentration of 0.5$2.5 \mu \mathrm{M}$ (Fig. 4 B). Consistently, qPCR analysis revealed that many hematopoietic genes, including scl, Imo2, runx1, gata1, $b H 1$, and $\beta$ major (adult globin), were up-regulated on day 6 after BAY 60-6583 treatment (Fig. 4 C). In contrast, BAY 606583 did not increase the expression of the mesoderm marker Cerberus, the expression of endothelial gene fli1 (Fig. 4 D). Interestingly, the expression of flk1 was decreased after BAY 606583 treatment (Fig. 4 D), consistent with the previous study showing the antagonist effect of $\operatorname{runx} 1$ on $f l k 1$ (Swiers et al., 2013). These data support a positive role of adenosine and its $A_{2 b}$ receptor in regulating $\mathrm{mESC}$ hematopoietic differentiation.

Next, we examined whether BAY 60-6583 promotes HSCs in the mouse AGM. A recent study performed expression profiling of the AGM HE at the onset of circulation (Swiers et al., 2013). We analyzed the microarray data and found that $A_{2 b}$ expression is high in $\mathrm{HE}$ and low in non-HE and hematopoietic progenitors (Fig. $4 \mathrm{E}$ ), similar to $\mathrm{A}_{2 \mathrm{~b}}$ expression from day 6 EBs. We confirmed $A_{2 b}$ expression in VECadherin $^{+}$cells from the E10.5 AGM by RT-PCR (Fig. 4 F). To test the effect of adenosine signaling on AGM HSPCs, AGM explants from E10.5 embryos were cultured with DMSO or BAY 60-6583, and HSC activity was measured by CFU 

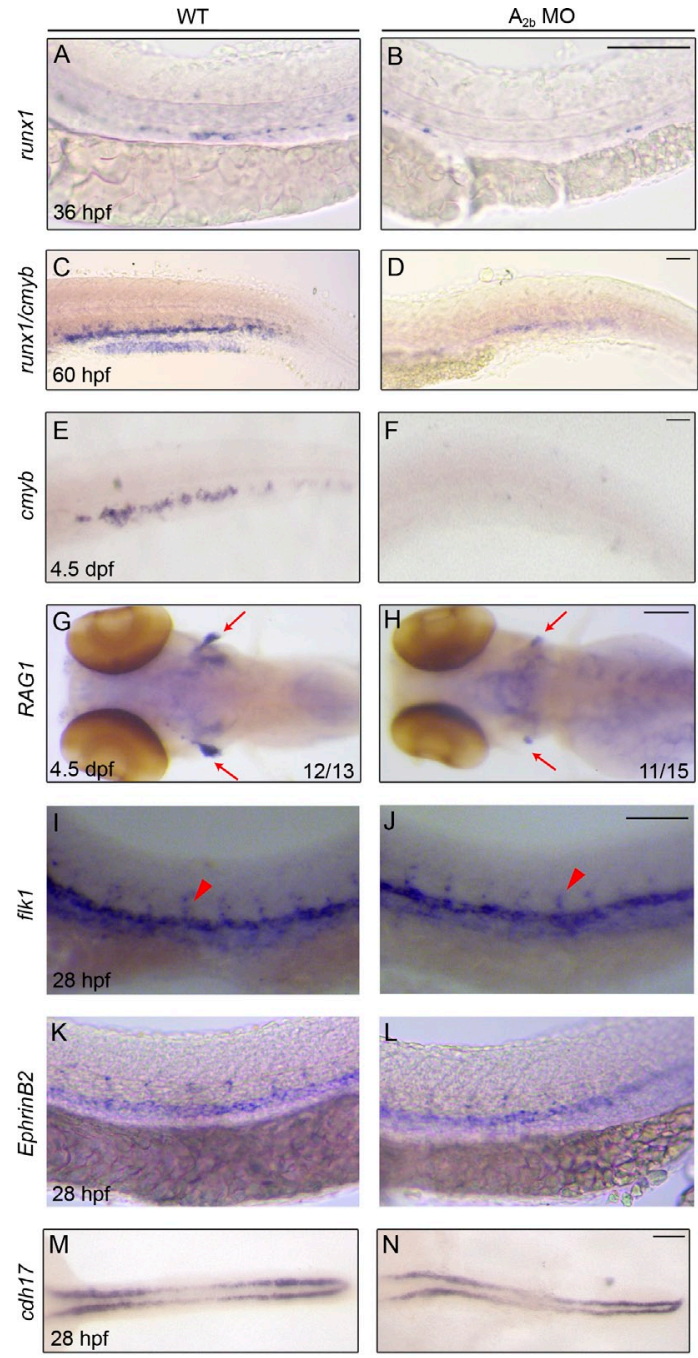
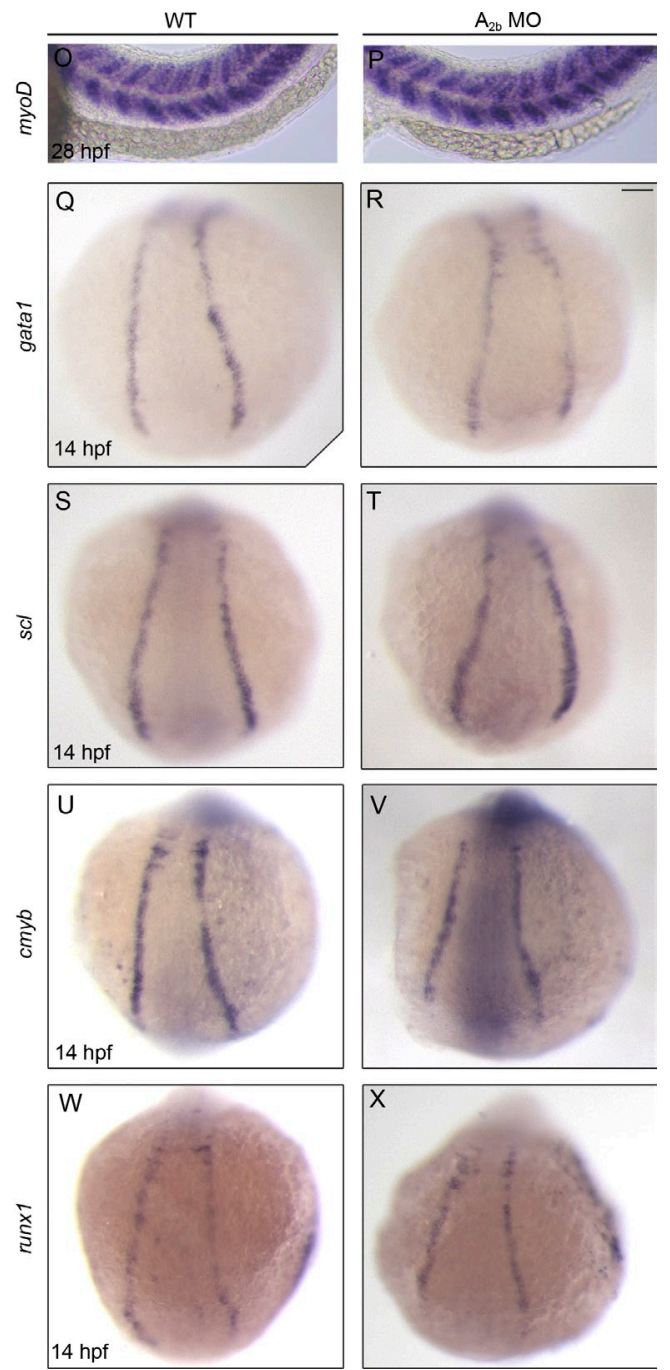

Figure 3. Adenosine signaling through $A_{2 b}$ specifically regulates HSPC development. (A-H) Control or $A_{2 b}$ MO-injected embryos stained for runx1

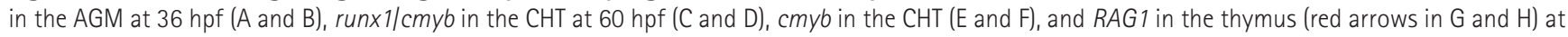
4.5 dpf. (I-X) Control or $\mathrm{A}_{2 \mathrm{~b}} \mathrm{MO}$-injected embryos stained for vasculature (flk1; I and J), dorsal aorta (ephrinB2; K and L), pronephros (cdh17; M and N), and somite (myoD; 0 and P), primitive hematopoiesis (gata 1 and scl; $\mathrm{Q}-\mathrm{T}$ ), and $c m y b$ and runx 1 (U-X) at the developmental stages indicated. In I and $\mathrm{J}$, red arrowheads mark intersegment staining. Bars, $100 \mu \mathrm{m}$.

culture (CFU-C) assay. As shown in Fig. 4 G, the addition of BAY 60-6583 significantly increased the numbers of erythroid, granulocyte/macrophage (GM), and multipotent progenitor (GEMM) colonies. Thus, adenosine promotes AGM HSCs in mouse.

\section{Adenosine is required for the EHT}

It is known that HSCs originate from HE via EHT. Recent time-lapse imaging studies have directly captured the emergence of HSPCs from $f l k 1: \mathrm{GFP}^{+}$aortic endothelial cells in live zebrafish embryos (Bertrand et al., 2010; Kissa and Herbomel, 2010). To examine whether adenosine regulates the EHT, we injected $\mathrm{A}_{2 \mathrm{~b}}$ MO into $\operatorname{Tg}(f k 1 l$ :GFP) embryos and used time-lapse imaging to track the formation of HSPCs between 32 and 60 hpf, as previously described (Kissa and Herbomel,
2010). As shown in Fig. 5 and Videos 1 and 2, in $A_{2 b}$-deficient embryos, flk1: GFP $P^{+}$endothelial cells initiated bending, and sometimes contraction, normally, albeit more rarely than in control embryos. We noticed that as the $f k 1: G F P^{+}$cells rounded up to become HSCs, a subset of these cells burst into small cellular pieces (Fig. 5, A-C). The bursting is very similar to the events seen in runx1-deficient embryos, in which the EHT event of $f k$ 1: GFP ${ }^{+}$cells abort into cell death (Kissa and Herbomel, 2010). These results suggested that adenosine signaling is required to achieve successful EHT.

To explore the relationship between adenosine signaling and runx1, we used an inducible runx1 Tg line (hsp70:runx1). After heat shock induction, runx 1 was expressed throughout the embryo (Fig. 5 D) and slightly increased the definitive hematopoietic marker $c m y b$ in control embryos (Fig. 5, E and F). In $\mathrm{A}_{2 \mathrm{~b}}$ 

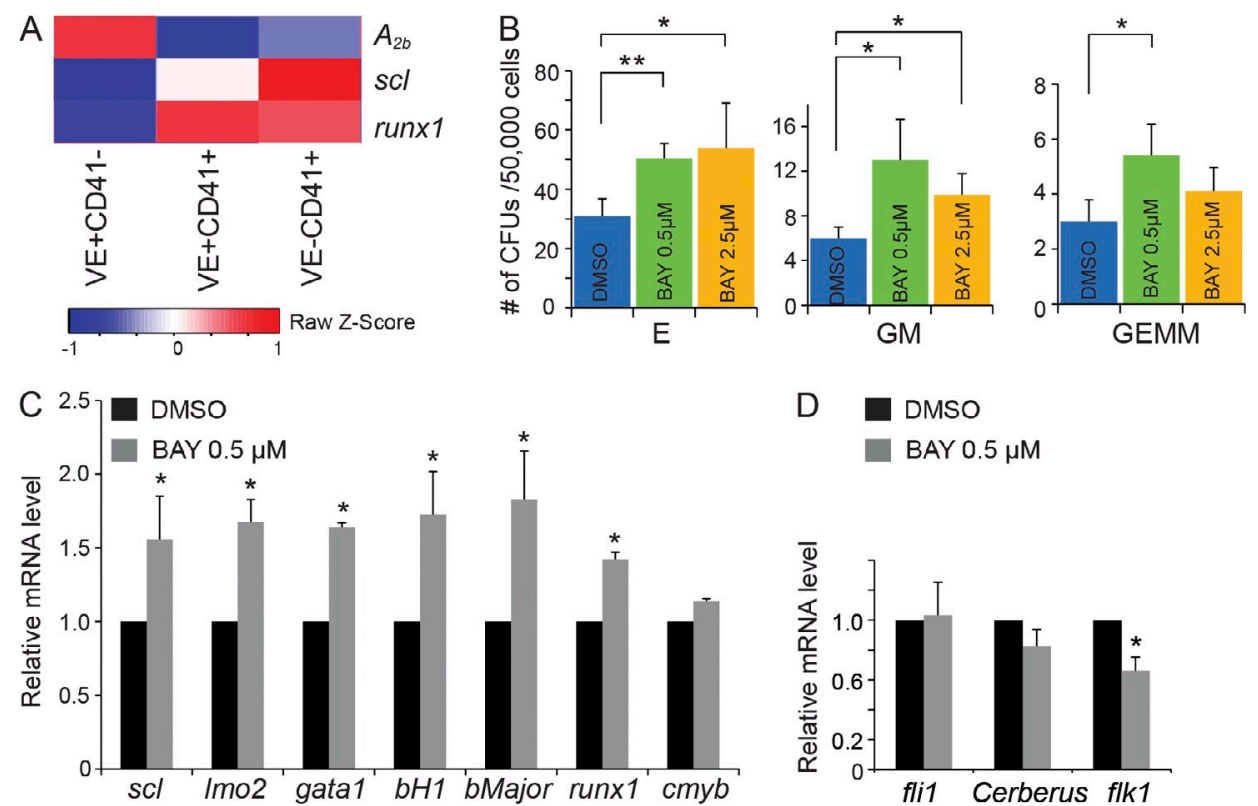

$\mathrm{E}$

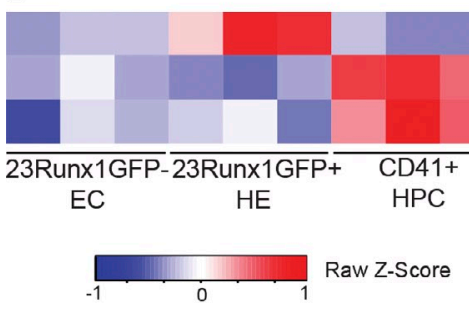

$\mathrm{F}$

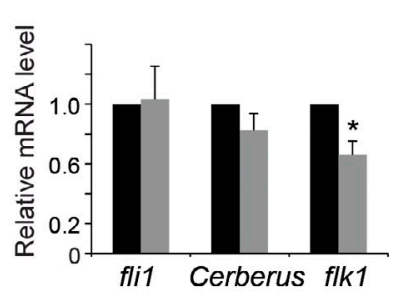

G
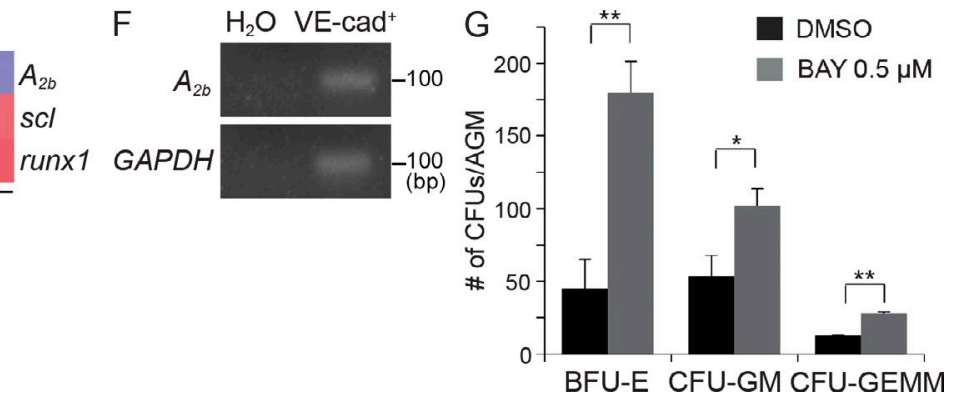

Figure 4. Treatment with an $A_{2 b}$ receptor agonist promotes hematopoietic development in mESC culture and AGM explants. (A) Microarray gene expression analysis of $A_{2 b}, s C l$, and runx 1 in sorted $V E$-cadherin ${ }^{+} \mathrm{CD} 41^{-}$, VE-cadherin ${ }^{+} \mathrm{CD} 41^{+}$, and $\mathrm{VE}$-cadherin- ${ }^{-} \mathrm{CD} 41^{+}$cells from day $6 \mathrm{EBs}$. (B) CFUs were measured $7 \mathrm{~d}$ after culture in M3434 of day 6 whole EBs treated with DMSO or BAY 60-6583 (0.5 $\mu \mathrm{M}$ and $2.5 \mu \mathrm{M}$; Student's $t$ test: ${ }^{*}, \mathrm{P}<0.05 ;{ }^{* *}, \mathrm{P}<0.01 ; n=3-5$ per group). (C) qPCR analysis of hematopoietic genes ( $\mathrm{scl}$, Imo2, gata 1, bH1, bMajor, runx 1 , and cmyb) measured in day 6 whole EBs treated with DMSO or $0.5 \mu \mathrm{M}$ BAY 60-6583 (Student's $t$ test: ${ }^{*}, \mathrm{P}<0.05 ; n=3$ per group). (D) qPCR analysis of fli1, cerberus, and flk1 measured in day 6 whole EBs treated with DMSO or $0.5 \mu \mathrm{M}$ BAY 60-6583 (Student's $t$ test: ${ }^{*}, \mathrm{P}<0.05 ; n=3$ per group). (E) Microarray gene expression analysis of selected genes in nonhemogenic endothelial cells (EC), HE, and hematopoietic progenitor cells (HPC) from Affymetrix microarrays under GEO accession no. GSE52075 (Swiers et al., 2013; $n=3$ ). (F) Expression of $A_{2 b}$ and GADPH genes by RT-PCR in VE-cadherin ${ }^{+}$cells purified from the E10.5 AGM. (G) CFU-C assay from E10.5 AGM explants. Numbers are per embryo (Student's $t$ test: ${ }^{*}, P<0.05 ;{ }^{* *}, P<0.01 ; n=4$ per group). The results are presented as mean $\pm \mathrm{SE}$.

MO-injected embryos, overexpression of runx1 showed a partial, but statistically significant rescue of $c m y b$ staining (Fig. 5, G-I). Thus, overexpressing runx 1 rescued HSPC formation in the absence of $A_{2 b}$, suggesting that runx 1 acts downstream of $A_{2 b}$.

\section{Adenosine signaling regulates $s \mathrm{cl}+$ hemogenic vascular endothelium}

The abortive EHT of flk1: GFP cells could result from a lack of hemogenic potential in these cells. We then examined whether adenosine regulates $\mathrm{HE}$ specification, the onset of EHT. The master hematopoietic transcriptional regulator $s c l$ is critical for establishing the hematopoietic potential in aorta endothelial cells and plays its role before runx 1 during definitive hematopoiesis. In zebrafish, an $\mathrm{N}$-terminal truncated $s c l-\beta$ isoform is essential for HSPC emergence. The $s c l$ reporter line $\operatorname{Tg}(s c l \beta$ : $d 2 e G F P)$ marks the hemogenic vascular endothelium, which is later transformed to HSPCs via EHT (Zhen et al., 2013). We altered adenosine signaling in $\operatorname{Tg}(s c l \beta: d 2 e G F P)$ embryos. In the absence of $\mathrm{A}_{2 \mathrm{~b}}, s c l-\beta: G F P^{+} \mathrm{HE}$ cell population was strongly reduced $(1.6 \pm 0.2$ /somite vs. $3.5 \pm 0.3$ /somite [con]; Fig. $6, \mathrm{~A}-\mathrm{B}^{\prime}$ and $\mathrm{H}$ ). Addition of $\mathrm{A}_{2 \mathrm{~b}}$ receptor agonist $\mathrm{BAY}$ $60-6583$ to wild-type embryos increased the number of $s c l-\beta$ : $G F P^{+}$in the AGM (4.6 $\pm 0.7 /$ somite vs. $3.5 \pm 0.5 /$ somite [con]; Fig. 6, C, $\mathrm{C}^{\prime}$, and $\mathrm{H}$ ). Overexpression of $s c l$ mRNA in zebrafish embryos partially rescued $\operatorname{run} x 1^{+} / c m y b^{+}$HSPCs in $\mathrm{A}_{2 \mathrm{~b}}$-deficient embryos (Fig. 6, D-G and I). These results indicate that adenosine signaling mediates $\mathrm{scl}^{+}$hemogenic vascular endothelium. Together, our data suggest that adenosine mediates HSPC formation via regulation of hematopoietic commitment of endothelial cells. 

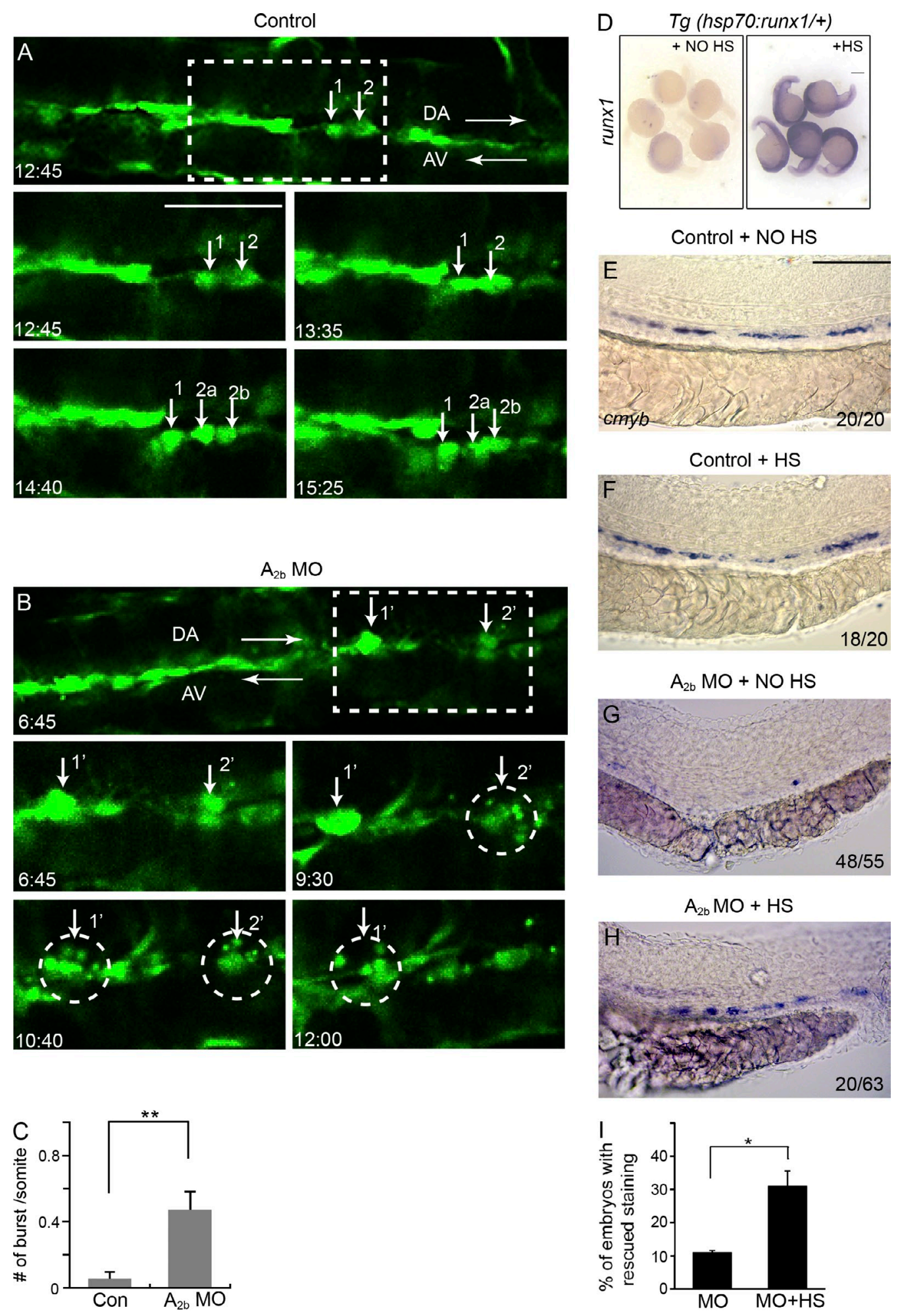

Figure 5. Adenosine signaling is required for EHT in zebrafish. (A and B) Still images from in vivo time-lapse confocal imaging of Tg(flk1:GFP) embryos between 32 and $48 \mathrm{hpf}$. Embryos are either uninjected (A) or injected with $A_{2 b} M 0$ (B). Numbers indicate recording time in hours and minutes. Arrows in A point to three aorta cells undergoing successful EHT. Cells $2 a$ and $2 b$ are the daughter cells of cell 2 . The two dorsal aorta cells $1^{\prime}$ and $2^{\prime}$ in $B$ initiate EHT and burst into pieces (marked by circles). (C) Quantification of the number of flk1:GFP+ cells per somite undergoing burst during the 16-h time-lapse period. The results are presented as mean \pm SE (Student's $t$ test: ${ }^{*}, P<0.01 ; n=6-8$ embryos per group). (D) $\operatorname{Tg}(h s p 70: r u n x 1)$ embryos stained for runx1 without heat shock (HS) induction or after heat shock induction. (E-H) Expression of cmyb at 36 hpf in Tg(hsp70:runx 1) embryos. Embryos were either uninjected ( $E$ and $F$ ) or injected with $A_{2 b} M O(G$ and $H)$. Embryos either received no heat shock treatment ( $E$ and $G$ ) or received heat shock induction 

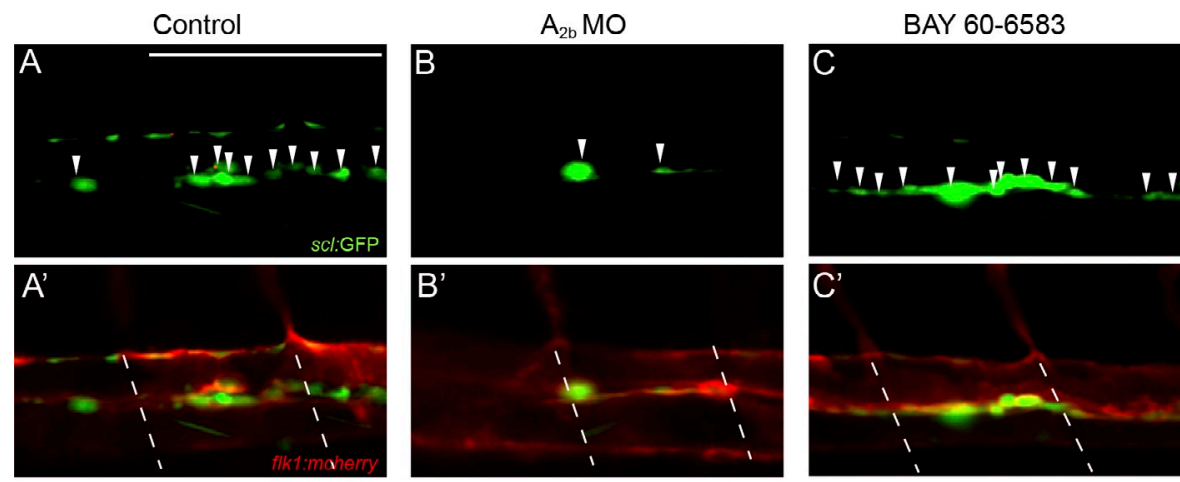

WT
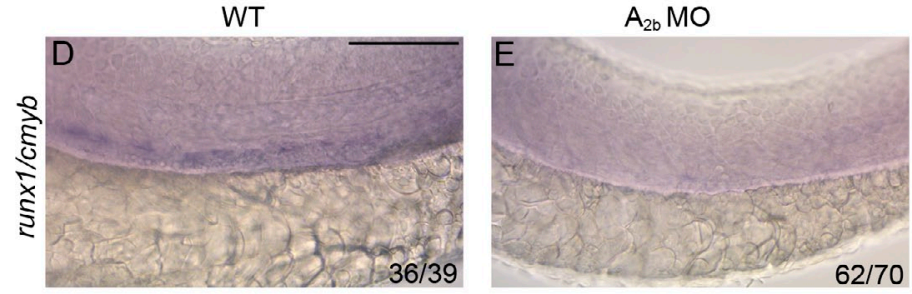

scl mRNA
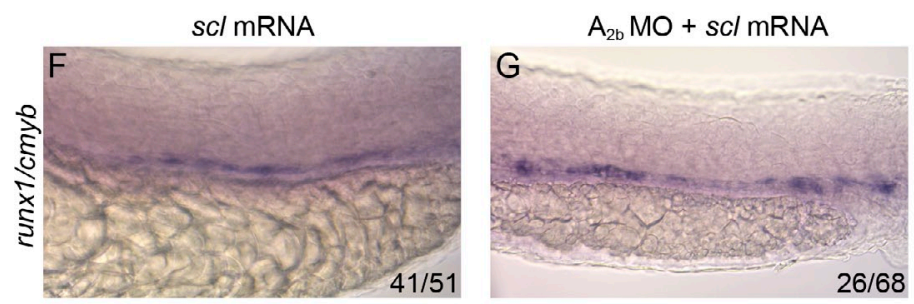

Figure 6. Adenosine signaling regulates hemogenic vascular endothelium. $\left(A-C^{\prime}\right)$ Confocal imaging of $\operatorname{Tg}(s \mathrm{~s} / \beta: d 2 \mathrm{e} G F P ;$ flk 1:mcherry) embryos at 30 hpf. Control embryos ( $A$ and $A^{\prime}$ ), embryos injected with $A_{2 b} M O$ (B and $\left.B^{\prime}\right)$, and embryos treated with $10 \mu \mathrm{M}$ BAY 60-6583 $\left(C\right.$ and $C^{\prime}$ ) are shown. Arrowheads indicate the hemogenic endothelial cells marked by $s c / \beta$ : GFP+. Dashed lines mark the somite boundaries. (D-G) Expression of runx $1 /$ cmyb in the AGM of control embryos (D), embryos injected with $A_{2 b} M O(E)$, and sc/ mRNA-injected (F) and $A_{2 b}$ $\mathrm{MO}$ - and scl mRNA-co-injected embryos (G). The numbers are combined from multiple experiments. $(H)$ Summary of the number of sc/ $\beta: G F P^{+}$hemogenic endothelial cells per somite. The results are presented as mean $\pm \mathrm{SE}$ (Student's $t$ test: ${ }^{*}, \mathrm{P}<0.05 ;{ }^{*}{ }^{*}, \mathrm{P}<0.01 ; n=$ 5-8 per group). (I) Quantification of the experiments in $\mathrm{E}$ and $\mathrm{G}$. The results are presented as the mean percentage of embryos with runx 11 cmyb staining as in $\mathrm{G} \pm \mathrm{SE}$ (Student's $t$ test: ${ }^{*}, \mathrm{P}<0.05 ; n=3$ experiments, around 20 embryos per experiment). Bars, $100 \mu \mathrm{m}$.
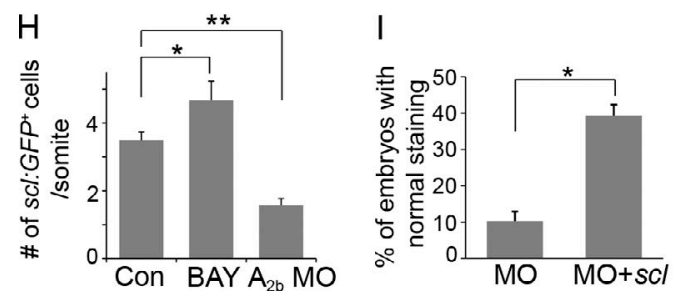

\section{Adenosine regulates CXCL8 production and mediates hematopoiesis via CXCL8}

In many cell types, adenosine promotes the production of $\mathrm{cy}-$ tokines, chemokines, and growth factors and often exerts its cellular effects through or in association with these factors (Adair, 2005). In vascular endothelial cells, $A_{2 b}$ activation modulates the production of several angiocrine factors (Feoktistov et al., 2002). One of the major factors is CXCL8 (also known as IL-8). CXCL8 is known as a potent stem cell-mobilizing agent (Laterveer et al., 1995), and it also increases the proliferation of hematopoietic progenitor cells in vitro (Hermouet et al., 2000). Human aortic endothelial cells (HAECs) express the $A_{2 b}$ receptor (Iwamoto et al., 1994), and we confirmed $\mathrm{A}_{2 \mathrm{~b}}$ expression by RT-PCR (not depicted). We treated HAECs with BAY 60-6583, which increased CXCL8 protein production
(Fig. 7 A). To demonstrate that $A_{2 b}$ regulates CXCL8 in zebrafish embryos, we examined cxcl8 transcripts. Knockdown of $\mathrm{A}_{2 \mathrm{~b}}$ strongly decreased $c x c l 8$ and runx 1 expression in $f k 1$ : $G_{F P} P^{+}$endothelial cells, but did not affect the expression of endothelial marker fli1 (Fig. 7 B). We next examined the function of CXCL8 in HSC development. Inhibition of cxcl8 with MO (Stoll et al., 2011) in zebrafish embryos strongly reduced run $x 1^{+} / c m y b^{+}$HSPCs in the AGM (Fig. 7, C-F) and the CHT (Fig. 7, I and J). Loss of CXCL8 did not have an effect on the development of the dorsal aorta at the time when HSPCs start to emerge (Fig. 7, K and L) and did not interfere with primitive hematopoiesis (not depicted), which supports a specific role of $c x c l 8$ in HSPC formation. In addition, we generated a CXCL8 mutation by a transcription activatorlike effector nuclease (TALEN) approach. This mutation

( $F$ and $H)$. The numbers are combined from multiple experiments. (I) Quantification of the experiments in $\mathrm{G}$ and $\mathrm{H}$. The results are presented as the mean percentage of embryos with rescued cmyb staining as in $\mathrm{H} \pm \mathrm{SE}$ (Student's $t$ test: ${ }^{*}, \mathrm{P}<0.05 ; n=3$ experiments, around 20 embryos per experiment). Bars: $(A$ and B) $50 \mu m$; (D) $250 \mu m$; (E-H) $100 \mu m$. 

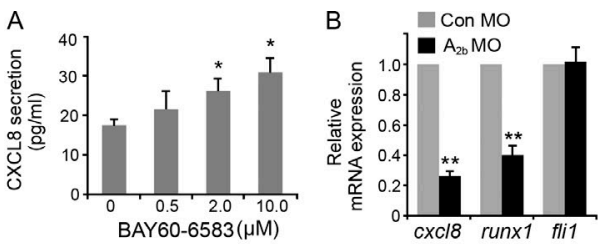

cxcl8 mRNA

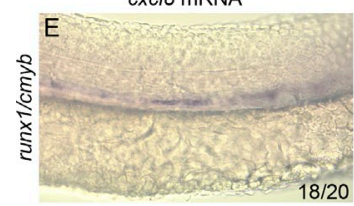

WT
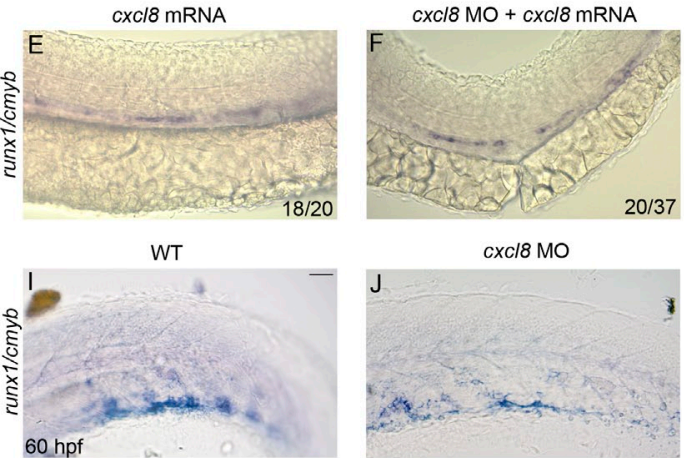

$c \times c / 8 \mathrm{MO}$

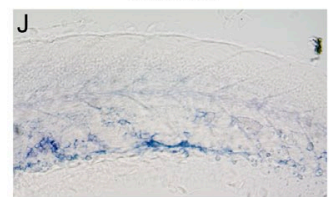

M

MTSKIISVCVIVFLAFLTIIEGMSLRGLAVDPR CRCIETESRRIGKHIKSVELFPPSPHCKDLEII ATLMTTGQEICLDPSAPWVKKIIDRIIVNRKP
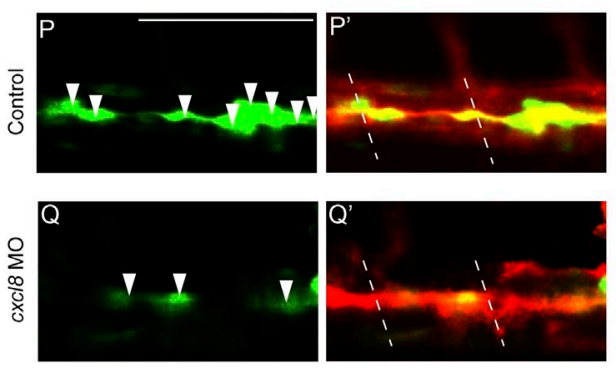

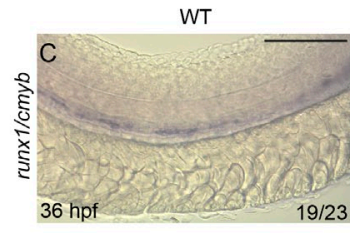

$A_{2 b} M O$

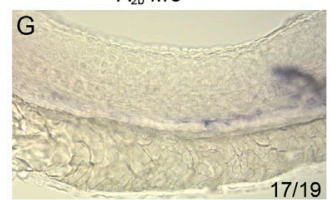

WT
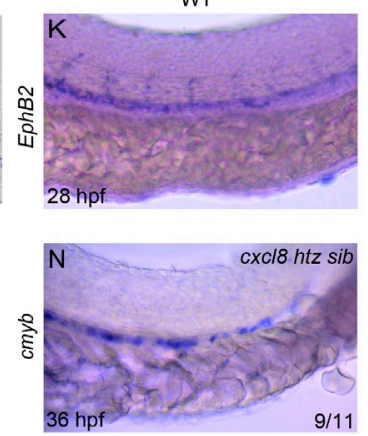

$9 / 11$

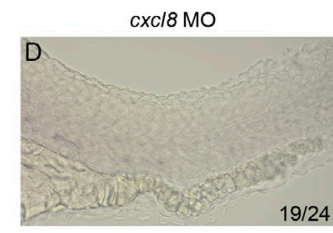

$\mathrm{A}_{2 b} \mathrm{MO}+c x c / 8 \mathrm{mRNA}$

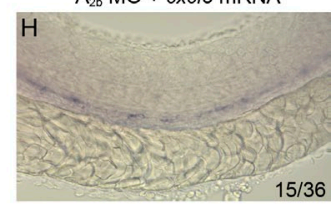

cxc/8 MO
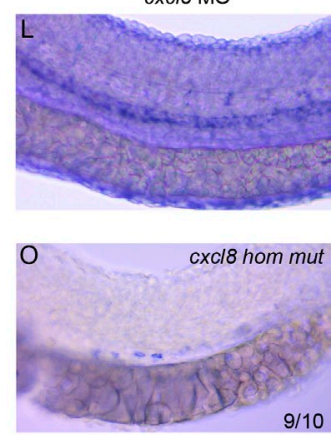

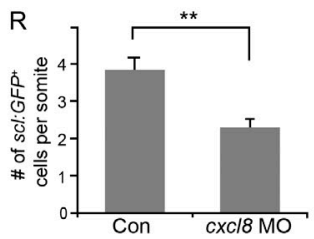

Figure 7. Adenosine mediates HSPC development by regulating CXCL8. (A) BAY 60-6583 induces CXCL8 secretion in HAECs (Student's $t$ test: $\left.{ }^{*}, \mathrm{P}<0.05 ; n=3\right)$. (B) Relative mRNA expression of $c x c / 8$, runx 1, and fli1 in FACS-sorted flk1:GFP+ cells in $\mathrm{A}_{2 b}$ M0-injected compared with control M0-injected embryos (Student's $t$ test: $\left.{ }^{* *}, \mathrm{P}<0.01 ; n=3\right)$. (C-H) Expression of runx $1 /$ cmyb at 36 hpf. Control embryos $(C)$ and embryos injected with $c x c / 8 \mathrm{MO}(\mathrm{D})$, injected with $c x c / 8 \mathrm{mRNA}(\mathrm{E})$, co-injected with $c x c / 8 \mathrm{MO}$ and $c x c / 8 \mathrm{mRNA}(\mathrm{F})$, injected with $\mathrm{A}_{2 b} \mathrm{MO}(\mathrm{G})$, and co-injected with $\mathrm{A}_{2 b} \mathrm{MO}$ and cxcl8 mRNA (H) are shown. (I and J) Expression of runx $1 / \mathrm{cmyb}$ in the CHT of control embryos or embryos injected with $c x c / 8 \mathrm{MO}$. (K and L) Control or cxc/8 M0-injected embryos stained for dorsal aorta (ephrinB2). (M) A CXCL8 TALEN mutation leads to the deletion of two amino acids (in yellow) in the conserved CXC domain. ( $\mathrm{N}$ and $\mathrm{O}$ ) Expression of cmyb at $36 \mathrm{hpf}$ in control sibling embryos and CXCL8 mutant embryos. htz, heterozygous; hom, homozygous. (P-Q') Confocal imaging of Tg(sc/ $\beta$ :d2eGFP; flk1:mcherry) embryos at 30 hpf. Control embryos (P and $\left.\mathrm{P}^{\prime}\right)$ and embryos injected with cxc/8 MO ( $\mathrm{Q}$ and $\left.\mathrm{Q}^{\prime}\right)$ are shown. Arrowheads indicate the hemogenic endothelial cells marked by sc/ $\beta$ :GFP+. Dashed lines mark the somite boundaries. (R) Summary of the number of sc/ $\beta$ :GFP+ hemogenic endothelial cells per somite (Student's $t$ test: ${ }^{* *}, \mathrm{P}<0.01 ; n=5$ per group). The results are presented as mean \pm SE. Bars, $100 \mu \mathrm{m}$.

leads to the deletion of two amino acids in the conserved CXC domain (Fig. 7 M; Fernandez and Lolis, 2002), which has been shown to be important for its tertiary structure. We found that the HSPC staining is reduced in CXCL8 mutant embryos compared with those in control siblings (Fig. 7, $\mathrm{N}$ and $\mathrm{O}$ ), in accordance with the defects we observed in CXCL8 MO knockdown embryos. Similar to loss of $\mathrm{A}_{2 \mathrm{~b}}$, loss of CXCL8 also reduced $\mathrm{sl}^{+}$hemogenic vascular endothelium (Fig. 7, P-R). More importantly, $\mathrm{cxcl} \mathrm{m} \mathrm{mRNA}$ restored HSCs and progenitors in the embryos that lack the $A_{2 b}$ (Fig. 7, G and H). These results suggest that adenosine signaling regulates CXCL8 production to mediate HSPC development.

\section{Adenosine regulates HSC formation via cAMP-PKA}

$A_{2 b}$ receptor is commonly coupled to adenylyl cyclase via $G$ protein subunit Gs and increases intracellular cAMP that activates PKA (Fredholm, 2007). We treated HAECs with BAY 60-6583 and performed chemiluminescence assay for cAMP activity. BAY 60-6583 induced cAMP production (Fig. 8 A). In addition, treatment of HAECs with $\mathrm{H} 89$ reduced BAY 60-6583-induced CXCL8 production (Fig. 8 B). To examine the role of cAMP in $\mathrm{A}_{2 \mathrm{~b}}$-mediated hematopoietic induction in embryos, we applied H89 to zebrafish embryos. H89 at $1 \mu \mathrm{M}$ decreased $r u n x 1^{+} / c m y b^{+}$HSPCs in the wild-type embryos and abolished the enhancement effect of NECA on 
A
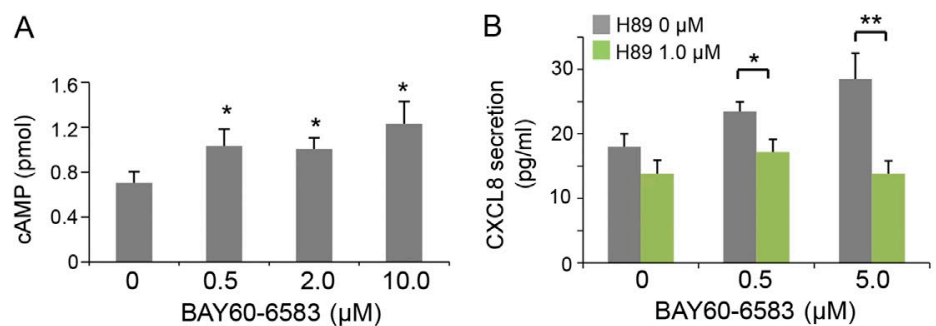

DMSO

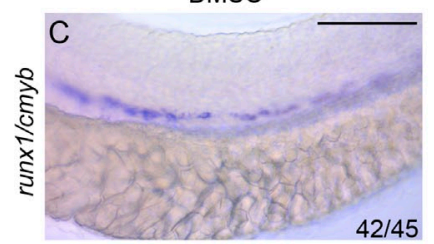

H89

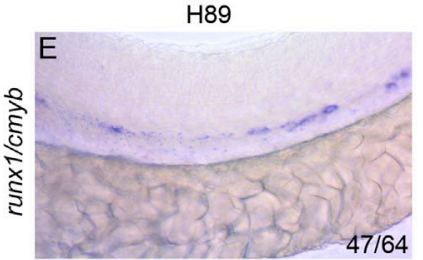

WT+DMSO

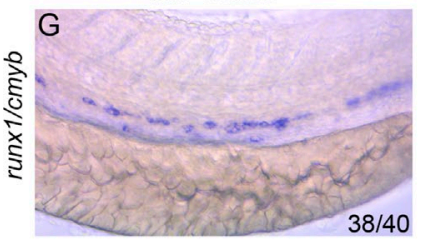

$\mathrm{A}_{2 \mathrm{~b}} \mathrm{MO}+\mathrm{DMSO}$

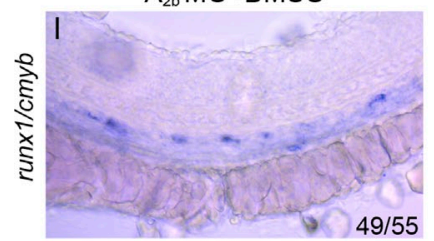

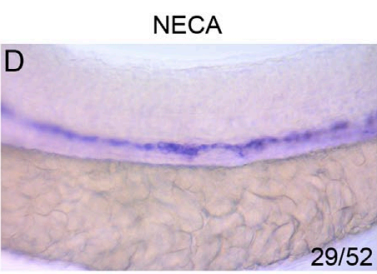
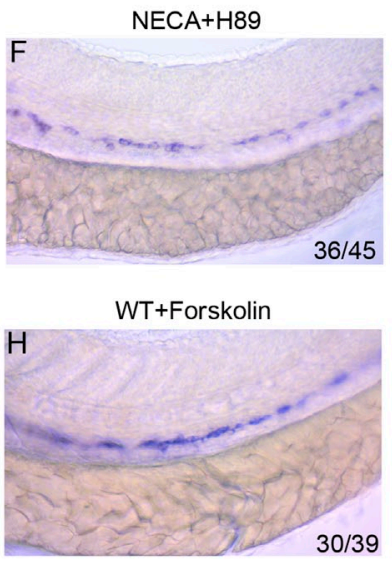

$\mathrm{A}_{2 b} \mathrm{MO}+$ Forskolin

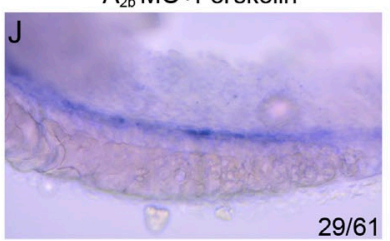

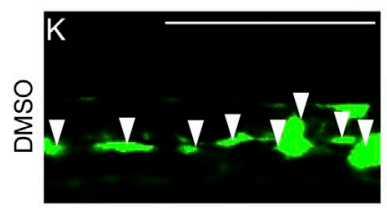

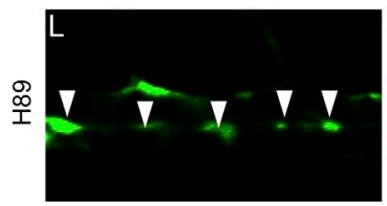

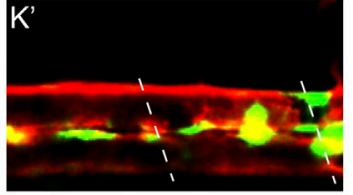

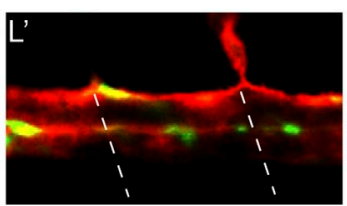

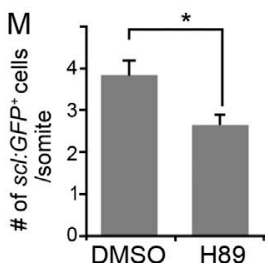

Figure 8. Adenosine-regulated HSPC emergence is a cAMP-PKA-dependent pathway. (A) CAMP luminescence assay in HAECs (Student's $t$ test: ${ }^{*}, \mathrm{P}<0.05 ; n=3$ ). (B) H89 inhibited CXCL8 level induced by BAY 60-6583 in HAECS (Student's $t$ test: ${ }^{*}, \mathrm{P}<0.05 ;{ }^{*}, \mathrm{P}<0.01 ; n=3$ ). (C-F) Expression of runx $1 /$ cmyb at $36 \mathrm{hpf}$. Wild-type embryos were treated with DMSO (C), $20 \mu \mathrm{M}$ NECA (D), or $1 \mu \mathrm{M}$ H89 (E) or co-treated with NECA and H89 (F) from 5-somite to $36 \mathrm{hpf}$. (G-J) Expression of runx $1 /$ cmyb at $36 \mathrm{hpf}$. Uninjected wild-type embryos treated with DMSO $(\mathrm{G})$ or $1 \mu \mathrm{M}$ forskolin $(\mathrm{H})$ and embryos injected with $\mathrm{A}_{2 b} \mathrm{MO}$ treated with DMSO (I) and forskolin $(J)$ are shown. (K-L') Confocal imaging of Tg(sc/3:d2eGFP; flk1: mcherry) embryos at $30 \mathrm{hpf}$. Embryos treated with DMSO ( $\mathrm{K}$ and $\mathrm{K}^{\prime}$ ) or $1 \mu \mathrm{M}$ H89 ( $\mathrm{L}$ and $\mathrm{L}^{\prime}$ ) are shown. Arrowheads indicate the hemogenic endothelial cells marked by sc/ $\beta$ :GFP'. Dashed lines mark the somite boundaries. (M) Summary of the number of sc/ $\beta$ :GFP+ hemogenic endothelial cells per somite (Student's $t$ test: ${ }^{*}, \mathrm{P}<0.05 ; n=5$ per group). The results are presented as mean \pm SE. Bars, $100 \mu \mathrm{m}$.
HSPCs (Fig. 8, C-F). We also applied forskolin, an activator of adenylyl cyclase commonly used to raise levels of cAMP, to $\mathrm{A}_{2 \mathrm{~b}} \mathrm{MO}-$ injected embryos. At $1 \mu \mathrm{M}$, forskolin increased runx $1 / \mathrm{cm} y b$ staining in the wild-type embryos and partially restored runx $1^{+} / c m y b^{+}$HSPCs in $\mathrm{A}_{2 \mathrm{~b}}$-dificient embryos (Fig. 8, G-J). In addition, inhibition of PKA activity with $\mathrm{H} 89$ reduced $\mathrm{sl}^{+}$hemogenic vascular endothelium (Fig. 8, K-M). These data support that cAMP-PKA acts downstream of $\mathrm{A}_{2 \mathrm{~b}}$ in promoting HSPC emergence.

Overall, these data indicate that adenosine signaling through $\mathrm{A}_{2 \mathrm{~b}}$ in endothelial cells activates the cAMP-PKA pathway, which up-regulates the production of cytokine CXCL8. In 
turn, CXCL8 promotes the emergence of HSPCs from the endothelium that is mediated by a transcriptional program including $s c l$ and runx1.

\section{DISCUSSION}

Adenosine signaling via its receptors has been studied in tissue regeneration. For example, adenosine promotes the regeneration of pancreatic $\beta$ cells (Andersson et al., 2012). In the hematopoietic system, adenosine enhances hematopoietic cell repair in adult mice after irradiation (Pospísil et al., 1993). Although components of adenosine signaling are expressed in the early embryo (Massé and Dale, 2012), the role of adenosine during embryogenesis, particularly at progenitor/stem cell development, has not been characterized previously. Our work has discovered an unrecognized role of adenosine in regulating HSPC development. We demonstrate that adenosine promotes HSPC emergence in zebrafish embryos and promotes hematopoietic differentiation in mESCs and in E10.5 AGM explants.

In the developing embryo, HSPCs derive from HE, a crucial intermediate population generated from endothelial cells. However, the signaling pathways that induce the hemogenic commitment of endothelial cells remain largely unknown. $s c$ is one of the early molecular determinants for HE (Lancrin et al., 2009). But little is known regarding how an scl event is regulated. Our experiments demonstrate that adenosine $A_{2 b}$ is expressed in vascular endothelial cells in zebrafish embryos and in VE-cadherin + /+23runx1-GFP ${ }^{+} \mathrm{HE}$ in the mouse AGM. Adenosine signaling modulates $s c l$-marked $\mathrm{HE}$, and ectopic expression of $s c$ partially rescues HSPC development in the absence of $A_{2 b}$. These findings support that adenosine through $\mathrm{A}_{2 \mathrm{~b}}$ regulates $s c l$-mediated hematopoietic commitment from aortic endothelium.

It is well known that adenosine stimulates the production of multiple growth factors and cytokines (Feoktistov and Biaggioni, 2011). In the AGM, endothelial cells are a probable source of the environmental factors that could affect HSC specification. We show that adenosine regulates CXCL8 production in the vascular endothelial cells. CXCL8 is often associated with neutrophil chemotaxis (Baggiolini and Clark-Lewis, 1992). It also has other cellular functions such as inducing rapid mobilization of HSCs in rodents (Laterveer et al., 1995). But its role during developmental hematopoiesis remains unexplored. We demonstrate that CXCL8 regulates $s l^{+} \mathrm{HE}$ and subsequent HSPC development during embryogenesis, similar to adenosine $A_{2 b}$. Moreover, cxcl 8 restores HSPC formation in $\mathrm{A}_{2 \mathrm{~b}}$-deficient embryos. Although adenosine may induce hematopoiesis through additional growth factors, our data suggest that adenosine acts at least partly through stimulating CXCL8 to promote HE and HSPC specification.

In addition, we show that cAMP-PKA is a downstream effector of adenosine signaling, and it underlies adenosineinduced CXCL8 production in endothelial cells, which is consistent with a previous report that the CXCL8 gene promoter has a cAMP-responsive element (CRE)-like site (Iourgenko et al., 2003). An accompanying study in this issue by Kim et al. demonstrated that shear stress activates the PKA-CREB pathway in VE-cadherin ${ }^{+}$cells, which promotes AGM HSC emergence. Recent studies indicate that shear stress can lead to the release of ATP, which is quickly converted to adenosine (Yegutkin et al., 2000; Wen et al., 2011). In our study, we found that the expression of $\mathrm{A}_{2 \mathrm{~b}}$ in vascular endothelial cells is maintained by blood flow. Therefore, it is possible that during HSC development, shear stress induces adenosine release, and its effect via $A_{2 b}$ contributes to the activation of the cAMP-PKA pathway in endothelial cells. We propose that cAMP-PKA-CREB regulates the production of growth factors and cytokines, which in turn promotes HSPC development controlled by a transcriptional program. It is also possible that cAMP-PKA-CREB may directly regulate $s c$, and CXCL8 and other factors may act to reinforce the transcriptional program. In any case, our experiments together highlight the critical role of the CAMP-PKA signaling pathway during vertebrate HSPC emergence.

It remains unknown how CXCL8 regulates HSPC emergence. Since it has been suggested that CXCL8 enhances cell growth and survival in different types of cells (Hermouet et al., 2000), it is possible that CXCL8 production in the AGM microenvironment affects the survival and/or proliferation of newly formed $\mathrm{sl}^{+}$hemogenic endothelial cells and HSPCs. We found that CXCL8 receptors $c x c r 1$ and $c x c r 2$ are expressed in $f l k 1^{+}$vascular endothelial cells in zebrafish embryos before HSPC emergence (unpublished data), which supports an autocrine signaling of CXCL8. The precise mechanism underlying CXCL8-mediated HSPC induction awaits further study.

In addition to acting in the formation of HE, our time-lapse imaging experiments suggest that adenosine might also regulate the transition of endothelial cells to hematopoietic cells. runx 1 is a central factor critical for the generation of HSCs from HE. It has been suggested that $s c l$ might activate runx1, directly or indirectly, to promote the conversion of endothelial cells to hematopoietic cells. In zebrafish embryos that lack runx 1, scl ${ }^{+} \mathrm{HE}$ remains intact (Zhen et al., 2013). In $\mathrm{A}_{2 \mathrm{~b}}$ - and CXCL8-deficient embryos, runx1 expression was decreased, and scl-marked hemogenic endothelial cells were also reduced. Our data support that the $\mathrm{A}_{2 \mathrm{~b}}-\mathrm{CXCL} 8$ axis acts upstream of $s c$ rather than runx1. It is intriguing that we found that overexpression of runx 1 restored HSPCs in $\mathrm{A}_{2 \mathrm{~b}}$-deficient embryos. This finding supports the idea that overexpression of runx 1 may bypass the requirement of $s c$-induced hematopoietic potential in endothelium.

Collectively, our experiments have discovered that adenosine regulates the generation of HSPCs in the early embryo. We provide evidence that it acts through $\mathrm{A}_{2 \mathrm{~b}}$ in endothelial cells to regulate $\mathrm{HE}$ and subsequent HSPC emergence, partly through up-regulation of CXCL8. These results provide novel insights into the signaling pathways that will be needed to derive HSCs from ESCs or pluripotent cells.

\section{MATERIALS AND METHODS}

Animals. Mice and zebrafish were maintained at Boston Children's Hospital according to institutional animal care and use committee protocols. The zebrafish wild-type Tubingen and transgenic lines flk1: GFP, flk1:mcherr,$c M \gamma b$ : GFP, sclß:de2GFP (Z. Wen, Hong Kong University of Science and Technology, Hong Kong, China), and $\mathrm{p} 53^{-/-}$were used in this study. 
Embryo chemical treatment. Wild-type and transgene embryos were treated from 5-somites to $36 \mathrm{hpf}$. 20-50 $\mu \mathrm{M}$ NECA, 10-20 $\mu \mathrm{M}$ CGS15943, and 5-10 $\mu \mathrm{M}$ BAY 60-6583 were obtained from Tocris Bioscience.

Confocal imaging. Live embryos were anesthetized in $0.04 \mathrm{mg} / \mathrm{ml} \mathrm{Tri-}$ caine, mounted in $1 \%$ low-melting agarose, and imaged with Leica confocal microscopes. $\mathrm{cMy}^{+} / \mathrm{fl}^{+}$cells were counted in projections of $\mathrm{z}$-stack images ( $n=5-10$ embryos per group).

In situ hybridization. In situ hybridization was performed as previously described (Thisse and Thisse, 2008). The images were taken with a Leica stereoscope and processed using Adobe Photoshop.

FACS sort cells and qPCR analysis. Flk1:GFP embryos were manually dissociated with $0.9 \%$ PBS containing Liberase (Sigma-Aldrich). $\mathrm{GFP}^{+}$cells were sorted into LS-TRIzol (Sigma-Aldrich). Total mRNA was extracted according to the manufacturer's protocol. Genomic DNA was removed using TURBO DNA-free kit (Life Technologies). cDNA was synthesized using SuperScript First-Strand synthesis system (Life Technologies). qPCR was performed using SYBR green supermix on a CFX96 real-time PCR detection system (Bio-Rad Laboratories) with gene-specific primers listed in Table S1. Relative expression level was determined.

MO and mRNA injection. MOs were ordered from Gene Tools and injected into 1- to 2-cell stage embryos. $\mathrm{A}_{2 \mathrm{~b}}$ translation blocking MO (5'-CAATGGCGATGTAGAGCGAATCCAT-3', $5 \mathrm{ng}$ ) was injected at 1- to 2-cell stage. $\mathrm{A}_{2 \mathrm{~b}}$ splice-blocking MO (5'-AAAGCGAGAAAGACTCACCTCAGGG-3', $2 \mathrm{ng}$ ) was designed against the splice donor site of exon 3. For RT-PCR analysis, cDNA templates were synthesized from five 24-hpf embryos. PCR primers were $5^{\prime}$-TCCTCACATTCCTGCTCCTGTC-3' (forward) and 5' -TCTTCATCTTCATTGGGGCATC-3' (reverse). IL-8 MO targeting exon 2-intron 2 junction sequence (5'-CGTATTAGTTTGAAAACTCACATGA-3' [Stoll et al., 2011]) was injected at $0.5 \mathrm{ng} /$ embryo. Standard control MO was purchased from Gene Tools.

mRNA was in vitro transcribed from linearized constructs using SP6 mMESSAGE mMACHINE kit (Ambion) and injected into the embryos at 1-cell stage. Zebrafish $A_{2 b}$ mRNA was injected at 50 pg/embryo. Human $\mathrm{A}_{2 \mathrm{~b}}$ mRNA was injected at $400 \mathrm{pg} /$ embryo. $s c l$ mRNA was injected at $150 \mathrm{pg} / \mathrm{embryo}$, and $\operatorname{cxcl} 8 \mathrm{mRNA}$ was injected at $200 \mathrm{pg} / \mathrm{embryo}$.

Methylcellulose colony formation. mESC maintenance and differentiation were modified from Nostro et al. (2008). The Bry-GFP cells were maintained in serum-free culture system for $3 \mathrm{~d}$ and trypsinized and aggregated to EBs using aggreWell (STEMCELL Technologies). After 24 h, EBs were grown in 6-well ultra-low attachment plate (Costar) with serum-free medium containing $2 \mathrm{ng} / \mathrm{ml}$ Activin, $3 \mathrm{ng} / \mathrm{ml} \mathrm{Wnt} 3 \mathrm{a}, 3 \mathrm{ng} / \mathrm{ml} \mathrm{BMP} 4$, and $1 \mu \mathrm{M}$ GSK269962A for $48 \mathrm{~h}$. After that, EBs were switched to serum-free medium containing $5 \mathrm{ng} / \mathrm{ml} \mathrm{VEGF}$ and $3 \mathrm{ng} / \mathrm{ml} \mathrm{BMP} 4$ for $72 \mathrm{~h}$. BAY 60-6583 was added between day 4 and day 6 during EB expansion. On day 6, EBs were dissociated to single cells and plated on M3434 methylcellulose. Colonies were counted on days 7-9 by morphology. For qPCR analysis, total RNA was extracted from day $6 \mathrm{EBs}$, and after cDNA synthesis, qPCR was performed using gene-specific primers as in Table S1.

AGM explant. Whole AGM region from day 10.5 embryos were cultured in IMDM (Invitrogen) containing $2 \%$ fetal calf serum and $50 \mathrm{U} / \mathrm{ml}$ penicillin/streptomycin overnight in the presence of $0.1 \% \mathrm{DMSO}$ or $0.5 \mu \mathrm{M} \mathrm{BAY}$ 60-6583. Tissues were maintained on a shaker in $5 \% \mathrm{CO}_{2}$ at $37^{\circ} \mathrm{C}$ in a humidified incubator. After 14-h (overnight) culture, AGM tissues were dissociated in $0.1 \%$ collagenase at $37^{\circ} \mathrm{C}$ for $1 \mathrm{~h}$ and plated using M3434 medium (STEMCELL Technologies) according to the manufacturer's instructions. Colonies were counted on days 7-9 by morphology.

Time-lapse video. Confocal microscopy was performed according to Kissa and Herbomel (2010). Embryos were mounted in 1\% LMP agarose with E3 media and tricaine as described previously (Bertrand et al., 2010). Embryos were imaged in MatTek glass-bottom multi-well plates (no. 1.5 coverslip). Time-lapse recording was performed at $28^{\circ} \mathrm{C}$. Microscopy was performed using a Yokogawa spinning disk confocal and Nikon inverted Ti microscope. The objective was a Nikon $20 \times$ air Plan-Apo differential interference contrast NA 0.75. Images were acquired with dual Andor iXon x3 EMCCD cameras $(512 \times 512$ pixels $)$ and NIS-elements software. Confocal z-stacks were acquired every 5 min over $16 \mathrm{~h}$ (between 32 hpf to $48 \mathrm{hpf}$ ) in 17 planes spaced by $2 \mu \mathrm{m}$. Multiple stage-matched embryos were imaged in parallel using a moving $\mathrm{XY}$ stage.

Heat shock of $\operatorname{Tg}($ hsp70:runx1). The embryos of hsp70:runx1, either uninjected or injected with $\mathrm{A}_{2 \mathrm{~b}} \mathrm{MO}$, were heat-shocked twice at $38.5^{\circ} \mathrm{C}$ for $30 \mathrm{~min}$ at 3 -somite stage and at $22 \mathrm{hpf}$. Embryos were then fixed at $36 \mathrm{hpf}$ for analysis.

Cell culture. Primary HAECs were cultured in EBM-2 medium-supplemented EGM-2 medium containing hEGF, hydrocortisone, hFGF-b, VEGF, R3-IGF-1, ascorbic acid, Heparin, fetal bovine serum, and Gentamicin/Amphotericin-B [GA] (Lonza). The cells were plated on gelatin-coated plates and kept under a humidified atmosphere of air $/ \mathrm{CO}_{2}(19: 1)$ at $37^{\circ} \mathrm{C}$.

Measurement of CXCL8 secretion. After HAECs were cultured to confluence, cells were serum starved overnight and suspended in serum-free medium containing $1 \mathrm{U} / \mathrm{ml}$ adenosine deaminase. Cells were treated with chemicals at the desired concentration and incubated for $6 \mathrm{~h}$. At the end of incubation, the culture media were collected, and the cells were lysed for total protein concentration measurement (DC protein assay; Bio-Rad Laboratories). CXCL8 concentration was measured using an ELISA kit (BioLegend).

cAMP luminescence assay. After cultured to confluence, HAECs were serum starved overnight. The cells were resuspended in fresh serum-free medium containing $1 \mathrm{U} / \mathrm{ml}$ adenosine deaminase and incubated at $37^{\circ} \mathrm{C}$ for $10 \mathrm{~min}$. Before chemical treatment, cells were treated with $200 \mu \mathrm{M}$ papaverine and incubated at $37^{\circ} \mathrm{C}$ for $10 \mathrm{~min}$ to block phosphodiesterase. Chemicals were added at the desired concentrations, and cells were incubated at $37^{\circ} \mathrm{C}$ for $15 \mathrm{~min}$. At the end of incubation, cells were lysed for cAMP ELISA assay according to the manufacturer's instructions (Enzo Life Sciences). A small portion of cell lysates was used to measure protein concentration.

Generation of CXCL8 mutant. The cxc18 mutant was generated with TALENs using backbones containing heterodimer endonucleases pCS2TAL3RR and pCS2TAL3DD (Dahlem et al., 2012) and the Golden Gate TALEN kit (Cermak et al., 2011). The two TALEN arms are designed to target Danio rerio CXCL8 (NCBI Gene ID: 100002946) at 5'-TGAGAGGTCTGGCTGTAGAT-3' and 5'-TGAAACAGAAAGCCGACGC-3'. CXCL8 mutant fish were identified by high-resolution melt analysis (Roche 0490963101). Primers used were forward, 5'-GAATGAGCTTGAGAGGTCTGGCTG-3'; and reverse, 5'-GGAGGGAAGAGCTCCACACTCTTTAT-3'. To sequence individual F0 fish, genomic DNA was isolated from a fin clip using $50 \mathrm{mM} \mathrm{NaOH}$. A PCR was run using the above HRMA primers, and the product was cloned into pCR4-TOPO (Life Technologies) and then transformed into DH5 $\alpha$ competent cells. Six to eight colonies were grown up and sequenced using the M13R primer $\left(5^{\prime}\right.$-CAGGAAACAGCTATGAC-3') to identify any mutations or deletions in the fish. The F2 heterozygous and homozygous mutant embryos were genotyped using the following primer pair: forward, $5^{\prime}$-GAACATGCAAAACCATATACTGC-3'; and reverse, 5'-AGGGGTCCAGACAGATCTCC- $3^{\prime}$. The PCR product was then sequenced to confirm the deletion of TCGCTG at positions 214 to 219.

Online supplemental material. Table $\mathrm{S} 1$ provides the primers sequences used in this study.Videos 1 and 2 are the time-lapse imaging of a control wildtype zebrafish embryo and an embryo in which $A_{2 b}$ expression was knocked down; the two videos demonstrate that in $\mathrm{A}_{2 \mathrm{~b}}$-deficient embryos, fewer 
flk1:GFP ${ }^{+}$cells initiate EHT, and the process ends with an explosion. Online supplemental material is available at http://www.jem.org/cgi/content/ full/jem.20141528/DC1.

We would like to thank Dr. Zilong Wen for providing the sc/ $\beta$ :GFPline, Ronald Matthium from Boston Children's Hospital flow cytometry laboratory for assistance with FACS, Dr. Dhvanit Shah for sih MO, members of the Zon laboratory for comments, and Dr. David Wiley, Julie Perlin, and Eva Fast for critical reading of the manuscript.

This work was supported by grants from the National Heart, Lung, and Blood Institute (NHLBI; R01 HL04880-21 to LI. Zon, P015P01HL32262-32, and 5U01 HL10001-05; and HL93149 to K. Ravid), National Institute of Diabetes and Digestive and Kidney Diseases (5P30 DK49216, R24 DK092760, and 5R01 DK53298), and Howard Hughes Medical Institute to L.I. Zon. S. Patterson was supported by a Cardiovascular Training Grant from the NHLBI (HL007969).

LI. Zon is a founder and stockholder of Fate Therapeutics Inc. and Scholar Rock.

Submitted: 10 August 2014

Accepted: 20 March 2015

\section{REFERENCES}

Adair, T.H. 2005. Growth regulation of the vascular system: an emerging role for adenosine. Am. J. Physiol. Regul. Integr. Comp. Physiol. 289:R283R296. http://dx.doi.org/10.1152/ajpregu.00840.2004

Andersson, O., B.A. Adams, D. Yoo, G.C. Ellis, P. Gut, R.M. Anderson, M.S. German, and D.Y. Stainier. 2012. Adenosine signaling promotes regeneration of pancreatic $\beta$ cells in vivo. Cell Metab. 15:885-894. http://dx.doi.org/10.1016/j.cmet.2012.04.018

Baggiolini, M., and I. Clark-Lewis. 1992. Interleukin-8, a chemotactic and inflammatory cytokine. FEBS Lett. 307:97-101. http://dx.doi.org/10 .1016/0014-5793(92)80909-Z

Bertrand, J.Y., N.C. Chi, B. Santoso, S. Teng, D.Y. Stainier, and D. Traver. 2010. Haematopoietic stem cells derive directly from aortic endothelium during development. Nature. 464:108-111. http://dx.doi.org/10.1038/ nature 08738

Boehmler, W., J. Petko, M. Woll, C. Frey, B. Thisse, C. Thisse, V.A. Canfield, and R. Levenson. 2009. Identification of zebrafish A2 adenosine receptors and expression in developing embryos. Gene Expr. Patterns. 9:144-151. http://dx.doi.org/10.1016/j.gep.2008.11.006

Boisset, J.C., W. van Cappellen, C. Andrieu-Soler, N. Galjart, E. Dzierzak, and C. Robin. 2010. In vivo imaging of haematopoietic cells emerging from the mouse aortic endothelium. Nature. 464:116-120. http:// dx.doi.org/10.1038/nature 08764

Cermak, T., E.L. Doyle, M. Christian, L. Wang, Y. Zhang, C. Schmidt, J.A. Baller, N.V. Somia, A.J. Bogdanove, and D.F. Voytas. 2011. Efficient design and assembly of custom TALEN and other TAL effector-based constructs for DNA targeting. Nucleic Acids Res. 39:e82. http://dx.doi .org/10.1093/nar/gkr218

Chen, A.T., and L.I. Zon. 2009. Zebrafish blood stem cells. J. Cell. Biochem. 108:35-42. http://dx.doi.org/10.1002/jcb.22251

Chen, M.J.,T.Yokomizo, B.M. Zeigler, E. Dzierzak, and N.A. Speck. 2009. Runx1 is required for the endothelial to haematopoietic cell transition but not thereafter. Nature. 457:887-891. http://dx.doi.org/10.1038/nature07619

Dahlem, T.J., K. Hoshijima, M.J. Jurynec, D. Gunther, C.G. Starker, A.S Locke, A.M. Weis, D.F. Voytas, and D.J. Grunwald. 2012. Simple methods for generating and detecting locus-specific mutations induced with TALENs in the zebrafish genome. PLoS Genet. 8:e1002861. http:// dx.doi.org/10.1371/journal.pgen.1002861

Feoktistov, I., and I. Biaggioni. 2011. Role of adenosine $\mathrm{A}_{2 \mathrm{~B}}$ receptors in inflammation. Adv. Pharmacol. 61:115-144. http://dx.doi.org/10.1016/ B978-0-12-385526-8.00005-9

Feoktistov, I., A.E. Goldstein, S. Ryzhov, D. Zeng, L. Belardinelli, T. Voyno-Yasenetskaya, and I. Biaggioni. 2002. Differential expression of adenosine receptors in human endothelial cells: role of $\mathrm{A}_{2 \mathrm{~B}}$ receptors in angiogenic factor regulation. Circ. Res. 90:531-538. http://dx.doi.org/ 10.1161/01.RES.0000012203.21416.14

Fernandez, E.J., and E. Lolis. 2002. Structure, function, and inhibition of chemokines. Annu. Rev. Pharmacol. Toxicol. 42:469-499. http://dx.doi.org/ 10.1146/annurev.pharmtox.42.091901.115838
Fredholm, B.B. 2007. Adenosine, an endogenous distress signal, modulates tissue damage and repair. Cell Death Differ. 14:1315-1323. http://dx.doi .org/10.1038/sj.cdd.4402132

Funakoshi, H., T.O. Chan, J.C. Good, J.R. Libonati, J. Piuhola, X. Chen, S.M. MacDonnell, L.L. Lee, D.E. Herrmann, J. Zhang, et al. 2006. Regulated overexpression of the A1-adenosine receptor in mice results in adverse but reversible changes in cardiac morphology and function. Circulation. 114:22402250. http://dx.doi.org/10.1161/CIRCULATIONAHA.106.620211

Glaser, T., A.R. Cappellari, M.M. Pillat, I.C. Iser, M.R. Wink, A.M. Battastini, and H. Ulrich. 2012. Perspectives of purinergic signaling in stem cell differentiation and tissue regeneration. Purinergic Signal. 8:523-537. http:// dx.doi.org/10.1007/s11302-011-9282-3

Haskó, G., J. Linden, B. Cronstein, and P. Pacher. 2008. Adenosine receptors: therapeutic aspects for inflammatory and immune diseases. Nat. Rev. Drug Discov. 7:759-770. http://dx.doi.org/10.1038/nrd2638

Hermouet, S., I. Corre, and E. Lippert. 2000. Interleukin-8 and other agonists of Gi2 proteins: autocrine paracrine growth factors for human hematopoietic progenitors acting in synergy with colony stimulating factors. Leuk. Lymphoma. 38:39-48.

Hofer, M., M. Pospísil, J. Netíková, V. Znojil, and J. Vácha. 1997. Enhancement of haemopoietic spleen colony formation by drugs elevating extracellular adenosine: effects of repeated in vivo treatment. Physiol. Res. 46:285-290.

Iourgenko, V., W. Zhang, C. Mickanin, I. Daly, C. Jiang, J.M. Hexham, A.P. Orth, L. Miraglia, J. Meltzer, D. Garza, et al. 2003. Identification of a family of cAMP response element-binding protein coactivators by genome-scale functional analysis in mammalian cells. Proc. Natl. Acad. Sci. USA. 100:12147-12152. http://dx.doi.org/10.1073/pnas.1932773100

Iwamoto, T., S. Umemura, Y. Toya, T. Uchibori, K. Kogi, N. Takagi, and M. Ishii. 1994. Identification of adenosine $A_{2}$ receptor-cAMP system in human aortic endothelial cells. Biochem. Biophys. Res. Commun. 199: 905-910. http://dx.doi.org/10.1006/bbrc.1994.1314

Kaimakis, P., M. Crisan, and E. Dzierzak. 2013. The biochemistry of hematopoietic stem cell development. Biochim. Biophys. Acta. 1830:23952403. http://dx.doi.org/10.1016/j.bbagen.2012.10.004

Kim, I., T.L. Saunders, and S.J. Morrison. 2007. Sox17 dependence distinguishes the transcriptional regulation of fetal from adult hematopoietic stem cells. Cell. 130:470-483. http://dx.doi.org/10.1016/j.cell.2007 .06 .011

Kim, P.G., C.E. Albacker, Y.F. Lu, I.H. Jang, Y. Lim, G.C. Heffner, N. Arora, T.V. Bowman, M.I. Lin, M.W. Lensch, et al. 2013. Signaling axis involving Hedgehog, Notch, and $\mathrm{Scl}$ promotes the embryonic endothelial-to-hematopoietic transition. Proc. Natl. Acad. Sci. USA. 110 E141-E150. http://dx.doi.org/10.1073/pnas.1214361110

Kim, P.G., H. Nakano, P.P. Das, M.J. Chen, R.G. Rowe, S.S. Chou, S.J. Ross, K.M. Sakamoto, L.I. Zon, T.M. Schlaeger, et al. 2015. Flowinduced protein kinase A-CREB pathway acts via BMP signaling to promote HSC emergence. J. Exp. Med. 212. http://dx.doi.org/10.1084/ jem.20141514

Kissa, K., and P. Herbomel. 2010. Blood stem cells emerge from aortic endothelium by a novel type of cell transition. Nature. 464:112-115. http://dx.doi.org/10.1038/nature08761

Koupenova, M., H. Johnston-Cox, and K. Ravid. 2012. Regulation of atherosclerosis and associated risk factors by adenosine and adenosine receptors. Curr. Atheroscler. Rep. 14:460-468. http://dx.doi.org/10.1007/ s11883-012-0263-y

Lancrin, C., P. Sroczynska, C. Stephenson, T. Allen, V. Kouskoff, and G. Lacaud. 2009. The haemangioblast generates haematopoietic cells through a haemogenic endothelium stage. Nature. 457:892-895. http:// dx.doi.org/10.1038/nature07679

Laterveer, L., I.J. Lindley, M.S. Hamilton, R. Willemze, and W.E. Fibbe. 1995. Interleukin- 8 induces rapid mobilization of hematopoietic stem cells with radioprotective capacity and long-term myelolymphoid repopulating ability. Blood. 85:2269-2275.

Massé, K., and N. Dale. 2012. Purines as potential morphogens during embryonic development. Purinergic Signal. 8:503-521. http://dx.doi.org/ 10.1007/s11302-012-9290-y

Medvinsky, A., and E. Dzierzak. 1996. Definitive hematopoiesis is autonomously initiated by the AGM region. Cell. 86:897-906. http://dx.doi .org/10.1016/S0092-8674(00)80165-8 
Mondal, B.C., T. Mukherjee, L. Mandal, C.J. Evans, S.A. Sinenko, J.A. Martinez-Agosto, and U. Banerjee. 2011. Interaction between differentiating cell- and niche-derived signals in hematopoietic progenitor maintenance. Cell. 147:1589-1600. http://dx.doi.org/10.1016/j.cell.2011.11.041

Nostro, M.C., X. Cheng, G.M. Keller, and P. Gadue. 2008. Wnt, activin, and BMP signaling regulate distinct stages in the developmental pathway from embryonic stem cells to blood. Cell Stem Cell. 2:60-71. http://dx.doi.org/10.1016/j.stem.2007.10.011

Okuda, T., J. van Deursen, S.W. Hiebert, G. Grosveld, and J.R. Downing. 1996. AML1, the target of multiple chromosomal translocations in human leukemia, is essential for normal fetal liver hematopoiesis. Cell. 84:321-330. http://dx.doi.org/10.1016/S0092-8674(00)80986-1

Orkin, S.H., and L.I. Zon. 2008. Hematopoiesis: an evolving paradigm for stem cell biology. Cell. 132:631-644. http://dx.doi.org/10.1016/ j.cell.2008.01.025

Porcher, C., W. Swat, K. Rockwell, Y. Fujiwara, F.W. Alt, and S.H. Orkin. 1996. The T cell leukemia oncoprotein SCL/tal-1 is essential for development of all hematopoietic lineages. Cell. 86:47-57. http://dx.doi .org/10.1016/S0092-8674(00)80076-8

Pospísil, M., M. Hofer, A. Vacek, J. Netíková, I. Pipalová, and S. Viklická. 1993. Noradrenaline reduces cardiovascular effects of the combined dipyridamole and AMP administration but preserves radioprotective effects of these drugs on hematopoiesis in mice. Physiol. Res. 42:333-340.

Pospísil, M., M. Hofer, A. Vacek, J. Netíková, J. Holá, V. Znojil, and L. Weiterová. 2001. Drugs elevating extracellular adenosine enhance cell cycling of hematopoietic progenitor cells as inferred from the cytotoxic effects of 5-fluorouracil. Exp. Hematol. 29:557-562. http://dx.doi.org/ 10.1016/S0301-472X(01)00622-1

Robu, M.E., J.D. Larson, A. Nasevicius, S. Beiraghi, C. Brenner, S.A. Farber, and S.C. Ekker. 2007. p53 activation by knockdown technologies. PLoS Genet. 3:e78. http://dx.doi.org/10.1371/journal.pgen.0030078

Rossi, L., V. Salvestrini, D. Ferrari, F. Di Virgilio, and R.M. Lemoli. 2012. The sixth sense: hematopoietic stem cells detect danger through purinergic signaling. Blood. 120:2365-2375. http://dx.doi.org/10.1182/ blood-2012-04-422378

Stoll, S.J., S. Bartsch, H.G. Augustin, and J. Kroll. 2011. The transcription factor HOXC9 regulates endothelial cell quiescence and vascular morphogenesis in zebrafish via inhibition of interleukin 8. Circ. Res. 108:13671377. http://dx.doi.org/10.1161/CIRCRESAHA.111.244095
Swiers, G., C. Baumann, J. O’Rourke, E. Giannoulatou, S. Taylor, A Joshi, V. Moignard, C. Pina, T. Bee, K.D. Kokkaliaris, et al. 2013 Early dynamic fate changes in haemogenic endothelium characterized at the single-cell level. Nat. Commun. 4:2924. http://dx.doi.org/10.1038/ ncomms 3924

Tamplin, O.J., E.M. Durand, L.A. Carr, S.J. Childs, E.J. Hagedorn, P. Li, A.D. Yzaguirre, N.A. Speck, and L.I. Zon. 2015. Hematopoietic stem cell arrival triggers dynamic remodeling of the perivascular niche. Cell. 160:241-252. http://dx.doi.org/10.1016/j.cell.2014.12.032

Thisse, C., and B. Thisse. 2008. High-resolution in situ hybridization to whole-mount zebrafish embryos. Nat. Protoc. 3:59-69. http://dx.doi.org/ 10.1038/nprot.2007.514

Tsai, F.Y., G. Keller, F.C. Kuo, M. Weiss, J. Chen, M. Rosenblatt, F.W. Alt, and S.H. Orkin. 1994. An early haematopoietic defect in mice lacking the transcription factor GATA-2. Nature. 371:221-226. http://dx .doi.org/10.1038/371221a0

Wang, Q., T. Stacy, J.D. Miller, A.F. Lewis, T.L. Gu, X. Huang, J.H. Bushweller, J.C. Bories, F.W. Alt, G. Ryan, et al. 1996. The CBF $\beta$ subunit is essential for CBF 22 (AML1) function in vivo. Cell. 87:697708. http://dx.doi.org/10.1016/S0092-8674(00)81389-6

Wen, J., A. Grenz, Y. Zhang, Y. Dai, R.E. Kellems, M.R. Blackburn, H.K Eltzschig, and Y. Xia. 2011. $\mathrm{A}_{2 \mathrm{~B}}$ adenosine receptor contributes to penile erection via $\mathrm{PI} 3 \mathrm{~K} / \mathrm{AKT}$ signaling cascade-mediated eNOS activation. FASEB J. 25:2823-2830. http://dx.doi.org/10.1096/fj.11-181057

Yegutkin, G., P. Bodin, and G. Burnstock. 2000. Effect of shear stress on the release of soluble ecto-enzymes ATPase and $5^{\prime}$-nucleotidase along with endogenous ATP from vascular endothelial cells. Br. J. Pharmacol. 129:921-926. http://dx.doi.org/10.1038/sj.bjp.0703136

Yoshimoto, M., and M.C. Yoder. 2009. Developmental biology: Birth of the blood cell. Nature. 457:801-803. http://dx.doi.org/10.1038/ $457801 \mathrm{a}$

Yue, R., H. Li, H. Liu, Y. Li, B. Wei, G. Gao, Y. Jin, T. Liu, L. Wei, J. Du, and G. Pei. 2012. Thrombin receptor regulates hematopoiesis and endothelial-to-hematopoietic transition. Dev. Cell. 22:1092-1100. http://dx.doi.org/10.1016/j.devcel.2012.01.025

Zhen, F., Y. Lan, B. Yan, W. Zhang, and Z. Wen. 2013. Hemogenic endothelium specification and hematopoietic stem cell maintenance employ distinct Scl isoforms. Development. 140:3977-3985. http://dx.doi.org/ 10.1242/dev.097071 